\title{
Dynamics and mechanisms of volatile organic compound exchanges in a winter wheat field
}

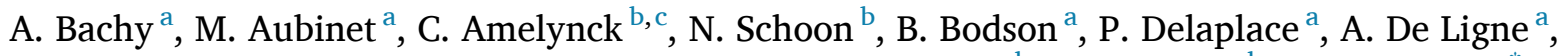 \\ A. Digrado ${ }^{a}$, P. du Jardin ${ }^{a}$, M.-L. Fauconnier ${ }^{a}$, A. Mozaffar ${ }^{\text {a,b }}$, J.-F. Müller ${ }^{b}$, B. Heinesch ${ }^{\text {a,* }}$ \\ a TERRA Teaching and Research Centre, Gembloux Agro-Bio Tech, University of Liège, Passage des déportés, 2, B-5030 Gembloux, Belgium \\ ${ }^{\mathrm{b}}$ Royal Belgian Institute for Space Aeronomy, Ringlaan 3, B-1180, Brussels, Belgium \\ ${ }^{\mathrm{c}}$ Dept. of Analytical Chemistry, Ghent University, Krijgslaan 281-S12, B-9000, Ghent, Belgium
}

\section{H I G H L I G H T S}

- The winter wheat field exchanged mainly methanol and other OVOCs.

- Warm conditions favoured methanol, acetaldehyde and acetone emissions.

- Fitted MEGAN v2.1 succeeded in reproducing their exchange dynamics.

- Warm conditions favoured acetic acid uptake.

- Senescence-induced emissions were reported for methanol and acetaldehyde.

\section{A R T I C L E I N F O}

\section{Keywords:}

BVOC

Winter wheat

Eddy covariance

Methanol

Crop

MEGAN v2.1 model

\begin{abstract}
A B S T R A C T
The understanding of biogenic volatile organic compound (BVOC) exchanges has become a key scientific issue because of their high reactivity and their impact in the atmosphere. However, so far, few studies have focused on BVOCs exchanged by agricultural species, and in particular by winter wheat, despite this species being the leading worldwide crop in terms of harvested area. This study for the first time investigated BVOC exchanges from winter wheat during most developmental stages of the plant. Fluxes were measured in Belgium at the ecosystem-scale using the disjunct eddy covariance by mass scanning technique, and a proton-transfer-reaction mass spectrometer for BVOC ambient mixing ratio measurements. As is usually observed for crops and grasses, the winter wheat field emitted mainly methanol, although bi-directional exchanges were observed. The second most exchanged compound was acetic acid which was captured during the entire growing season. Bi-directional exchanges of acetaldehyde and acetone were also reported. Terpene exchanges were 22 times smaller than oxygenated VOC (OVOC) exchanges. For all compounds, the exchanges were the most pronounced at the end of the growing season, i.e., under warm, dry and sunny conditions. Senescence-induced emissions were furthermore observed for methanol and acetaldehyde. For all investigated OVOCs, the exchanges very likely originated from both the soil and the plants. Despite their mixed origin, the MEGAN (Model of Emissions of Gases and Aerosols from Nature) v2.1 up-scaling model could adequately reproduce the methanol, acetaldehyde and acetone exchanges measured at this site during the mature and senescence phases of the plant, when the standard emission factor and the leaf age factor were adapted based on the measurements. In contrast, the model failed to reproduce the measured acetic acid exchanges. When the standard emission factor values currently assigned in MEGAN were applied, however, the exchanges were largely over-estimated for all compounds.
\end{abstract}

\section{Introduction}

For the past few decades, volatile organic compound exchange quantification and understanding have been scientific issues of interest due to the high reactivity of these compounds in the troposphere and their resulting impact on atmospheric chemistry and pollutants like PAN (Mellouki et al., 2015), ozone (Fry et al., 2012; Isaksen et al., 2009; Mellouki et al., 2015; Sartelet et al., 2012; Tsimpidi et al., 2012),

\footnotetext{
* Corresponding author.

E-mail address: bernard.heinesch@uliege.be (B. Heinesch).
} 
methane lifetime (Isaksen et al., 2009; Williams et al., 2013) or secondary organic aerosol formation (Mellouki et al., 2015; Sartelet et al., 2012; Ziemann and Atkinson, 2012).

VOCs are mainly emitted by terrestrial plants (Fowler et al., 2009; Mellouki et al., 2015). These compounds are therefore grouped under the term biogenic volatile organic compounds (BVOC). BVOCs include a wide set of molecules which arise from different plant metabolic pathways (Fowler et al., 2009; Niinemets et al., 2013). Because the plant BVOC exchange compositions and magnitudes vary between plants (Fowler et al., 2009; Monson et al., 2013), they must be quantified over a broad range of plants and ecosystems in order to achieve good accuracy in BVOC exchange predictions for terrestrial ecosystems (Lerdau and Slobodkin, 2002; Osborne et al., 2010; Wohlfahrt et al., 2015).

Although they account for $38 \%$ of the land area (FAOSTATS, 2013), agricultural ecosystems have been poorly investigated. Most BVOC studies that have investigated crop species were conducted at the leafscale (Crespo et al., 2013; Graus et al., 2013; Hu et al., 2018; Karl et al., 2005; Kesselmeier et al., 1998; König et al., 1995; Miresmailli et al., 2013; Mozaffar et al., 2017) or lasted only a few days and encompassed poorly contrasted weather conditions (Copeland et al., 2012; Graus et al., 2013), a noticeable exception being the recent study by Wiß et al. (2017) on maize using whole plant chambers. In particular, winter wheat is the most important crop worldwide in terms of harvested area, alone representing more than $14 \%$ of all agricultural lands (FAOSTATS, 2015), yet has only been investigated in five BVOC studies (Gallagher et al., 2000; Gonzage Gomez et al., 2019; König et al., 1995; Wang et al., 2015; Wenda-Piesik, 2011). In addition, four out of these five studies didn't measured oxygenated volatile organic compound (OVOC) exchanges, although OVOCs are known to be the main compounds exchanged by crops. As a result, the knowledge of BVOC exchanges from this species remains very scarce.

Additionally, BVOC up-scaling models like MEGAN v2.1 (Model of Emissions of Gases and Aerosols from Nature (Guenther et al., 2012)) or ORCHIDEE (Organizing Carbon and Hydrology in Dynamic EcosystEm, Messina et al., 2016) are widely used by atmospheric chemistry models to estimate the BVOC budget from terrestrial lands and evaluate the impact of BVOCs on atmospheric chemistry and the climate (Henrot et al., 2017; Makkonen et al., 2012; Richards et al., 2013; Squire et al., 2014; Williams et al., 2013). A non-exhaustive list compiling more than 30 research articles using the MEGAN v2.1 model is available on the web page: http://lar.wsu.edu/megan/application.html). Both models are semi-empirical and rely on plant exchanges. To summarise, a standard exchange rate (standard emission factor or $S E F$ ) is defined under standard phenological and meteorological conditions for each compound and each plant functional type, including croplands. The $S E F$ is then modulated for diverse phenological (leaf age factor) and meteorological conditions (environmental factor), by applying multiplicative semi-empirical algorithms. If these models are to achieve realistic BVOC exchange rates for terrestrial ecosystems, they should use representative $S E F$ s for each major ecosystem in the world, including croplands. In addition, the algorithms designed to simulate the BVOC exchanges beyond these standard conditions should be consistent with the dynamics actually observed under field conditions.

Flux datasets are used to derive species specific SEFs but different algorithms and different implementation options can lead to very different SEFs for a given species, even when sticking to model formulations adapted to micro-meteorological flux measurements, as was shown for isoprene recently by Langford et al. (2017). More important in the context of this study, the SEFs currently assigned for croplands do not rely on OVOC flux measurements taken from major crops. For example, Stavrakou et al. (2011) assigned a SEF for croplands derived from alfalfa, although this species accounts for only $1 \%$ of the cultivated area worldwide (FAOSTATS). Karl et al. (2009) made a comprehensive $S E F$ inventory for Europe. However, these authors noticed that because of the lack of information, the $S E F$ values assigned for croplands do not correspond to actually observed fluxes but to 'default' values. Recently, the SEFs used in the model ORCHIDEE have been updated for several plant functional types, including croplands (Messina et al., 2016). The new SEFs were based on a detailed literature survey, but, probably because of a lack of available and usable data for these ecosystems, the SEFs assigned for croplands still relied on default values or on flux values measured for minor crops (in terms of harvested area). From a BVOC flux measurement study conducted on a maize field, which is the second most important worldwide crop, it was also concluded that these SEFs may be highly over-estimated for C4 crops grown in North-West Europe (Bachy et al., 2016). As a consequence, there is a real need to quantify SEFs from flux measurements for major crops, including winter wheat.

The MEGAN model was historically designed to reproduce plant emissions of isoprene (Guenther et al., 2006). Since then, the model has been adapted for other compounds including OVOCs in the v2.1 version (Guenther et al., 2012), but the emissions algorithms are essentially identical to those of isoprene, although the physiological pathways (Niinemets et al., 2013) and the flux temporal dynamics (Brilli et al., 2014) differ between compounds. To our knowledge, the ability of the MEGAN v2.1 model to reproduce the methanol exchanges from a crop species has never been tested. It would thus be worthwhile to test the ability of these models to reproduce the OVOC exchanges measured from crops at an ecosystem-scale.

This study seeks to fill these gaps by presenting, for the first time, BVOC exchanges measured at the ecosystem-scale for a winter wheat field during contrasting developmental stages of the plant, with a particular focus on OVOC exchanges. First, the BVOC exchange composition and dynamics throughout the plant development will be presented. Senescence-induced effects will be specifically discussed. Second, a comparison will be made of the OVOC exchange rates with those reported in the literature for other agricultural species. Lastly, the ability of the MEGAN v2.1 up-scaling model (Guenther et al., 2012) to reproduce the measured OVOC exchanges will be evaluated.

\section{Materials and methods}

\subsection{Measurement campaign}

BVOC fluxes were measured at the Lonzée Terrestrial Observatory (LTO), which is located in the agricultural silt loam region of Belgium $\left(50^{\circ} 33^{\prime} 08^{\prime \prime} \mathrm{N}, 4^{\circ} 44^{\prime} 42^{\prime \prime} \mathrm{E}\right)$. Briefly, the site is a production field of approximately 12 ha located on a plateau. It is managed following the usual practices of the region and includes continuous micrometeorological measurements, as well as $\mathrm{CO}_{2}$ and water vapour fluxes by eddy covariance since 2004 . More information about this site can be found in Moureaux et al. (2006).

Winter wheat (Triticum aestivum L., variety Matrix2cv) was sown on 25 October 2012 and harvested on 12 August 2013. Liquid nitrogen fertiliser was applied on 16 April, 7 May and 21 May 2013. Weeding was applied on 17 April 2013, and fungicide on 8 June and 26 June 2013. During these events, the BVOC flux measurements were stopped for several days in order to prevent pollution of the instruments.

The BVOC flux measurement campaign extended from 5 March 2013 to 28 July 2013 . However, due to technical constraints, it was periodically interrupted $(15 \%, 4 \%, 8 \%, 17 \%$ and $30 \%$ of the time no data were available because of calibration, maintenance, failure, nitrogen/phytosanitary product application and site sharing with other projects, respectively, and $4 \%$ of the data were discarded after quality filtering). The data coverage thus amounted to $23 \%$ or 1645 data points. BVOC exchanges were nevertheless measured during all main developmental stages of the plant, with the exception of the tillering stage (Fig. 2). This allowed the evaluation of BVOC exchange composition and magnitude throughout the plant development.

\subsection{BVOC flux measurements}

BVOC fluxes were calculated at the ecosystem-scale from wind speed 
velocity and mixing ratio measurements, with a half-hour step, using the disjunct eddy covariance by mass scanning technique (DEC-MS). According to that technique, fluxes correspond to the covariance between the vertical wind velocity, which was measured with a sonic anemometer (Solent Research R3, Gill Instruments Lymington, UK) mounted on a mast at $2.7 \mathrm{~m}$ height, and the concentration (in the present case, the mixing ratio $M R$ was measured) of the target gases, which was measured with a high sensitivity proton-transfer-reaction mass spectrometer (hsPTR-MS, Ionicon Analytik GmbH, Innsbruck, Austria).

The instrumental set-up, flux calculation, filtering and error evaluation used for this campaign were identical to those used in two former BVOC flux measurement campaign performed on a maize field and on bare soil at the same site and were thoroughly described in Bachy et al. (2016) and Bachy et al. (2018). Time-lag determination, correction for low-pass filtering and uncertainty analysis are particularly important aspects, especially when dealing with disjunct eddy-covariance (Rinne and Ammann, 2012). The time lag between the wind and the concentration data streams was calculated using the technique recommended by Bamberger et al. (2010), Hörtnagl et al. (2010) and Taipale et al. (2010), whereby time lags are determined by covariance maximisation, using the disjunct concentrations to compute the cross-correlation curve and applying a smoothing function to that curve prior to peak determination. The fluxes were corrected for high frequency loss with theoretical transfer functions for deducing a cut-off frequency of the system following Moncrieff et al. (1997), the reference co-spectrum chosen being the one proposed in Kaimal and Finnigan (1994) which was found to be very similar to the local sensible heat co-spectrum. The half-power cut-off frequency was estimated to be $0.4 \mathrm{~Hz}$. The resulting correction factor ranged between 1 and 1.8, with an average of 1.23 for all measurement periods. The potential systematic flux error was estimated by comparing the water vapour flux obtained from the measurements with the hs-PTR-MS with that based upon the measurements with an infra-red gas analyzer, following Ammann et al. (2006). The slope of the relationship between the water vapour fluxes estimated with both instruments did not significantly differ from 1 , leading to the conclusion that the fluxes were not biased. Finally, the individual flux random error $(\sigma)$ was equated to the detection limit, following the technique described in Spirig et al. (2005). Using this detection limit for characterizing the noise level, the methanol, acetaldehyde, acetone, acetic acid, m/z 69 and monoterpenes flux signal to noise ratio were on average $2.2,1.9$, 2.4, 2.6, 2.4 and 4.6 for the whole dataset, respectively, and 4.8, 4.1, 4.1, $4.2,3.9,4.1$ if computed for the fourth quartile of absolute flux magnitude. Flux random error propagation and its final impact on flux average computation are discussed in section 2.4. For further details, the reader is redirected to Bachy et al. (2016) and Bachy et al. (2018). The only difference from those studies is that the shelter containing the hs-PTR-MS was located North-East of the mast (instead of South-East). That North-East sector is the second dominant wind sector at LTO, but $\mathrm{CO}_{2}$ co-spectra analyses did not reveal any significant influence of the shelter location on the fluxes. We therefore concluded that the shelter was located far enough away from the mast and that it did not disturb the fluxes.

Thirteen ion species were measured, each with a dwell time of $0.2 \mathrm{~s}$. This resulted in a flux measurement frequency of $0.25 \mathrm{~Hz}$. Eight species are listed in Table 1 with their potentially contributing BVOCs. The five other species were related to various green leaf volatile compounds. Because we lacked calibration data to quantify their exchange rates, they were not included in this paper. Beside the primary ion and water vapour signal, six ion species are therefore presented in this paper, representing a limited number of compounds in potentially a much wider chemical complexity. Full screening of this complexity has recently been facilitated by the advent of online measurements by timeof-flight mass spectrometers although available studies are still limited to short time periods (Brilli et al., 2014; Gonzaga Gomez et al., 2019; Park et al., 2013; Ruuskanen et al., 2011). On herbaceous crops and grasses (Gonzaga Gomez et al., 2019; Ruuskanen et al., 2011), they
Table 1

$\mathrm{m} / \mathrm{z}$ ratio of ion species measured at LTO and their potentially contributing compound(s).

\begin{tabular}{lll}
\hline $\mathrm{m} / \mathrm{z}$ & Ion species & Potentially contributing compound(s) \\
\hline 21 & $\mathrm{H}_{3}^{18} \mathrm{O}^{+}$ & 3rd isotope of the 1st proton hydrate \\
33 & $\mathrm{CH}_{5} \mathrm{O}^{+}$ & Methanol \\
39 & $\mathrm{H}_{5}^{16} \mathrm{O}^{18} \mathrm{O}^{+}$ & 3rd isotope of the 2nd proton hydrate \\
45 & $\mathrm{C}_{2} \mathrm{H}_{5} \mathrm{O}^{+}$ & Acetaldehyde (ACD) \\
59 & $\mathrm{C}_{3} \mathrm{H}_{7} \mathrm{O}^{+}$ & Acetone, propanal \\
61 & $\mathrm{C}_{2} \mathrm{H}_{5} \mathrm{O}_{2}^{+}$ & Acetic acid \\
69 & $\mathrm{C}_{5} \mathrm{H}_{9}^{+}$ & Isoprene, methyl butenols, pentenols, methylbutanal \\
137 & $\mathrm{C}_{10} \mathrm{H}_{17}^{+}$ & Monoterpenes (MT) \\
\hline
\end{tabular}

confirmed that methanol dominates the exchanges and that the other selected compounds represent a significant part of the exchanges excluding methanol.

Regular calibrations of the hs-PTR-MS for the other species but acetic acid, at ambient relative humidity, were performed every 3-4 days. Methanol, acetaldehyde, acetone, isoprene and monoterpenes were explicitly calibrated from a gravimetrically prepared diluted VOC mixture in nitrogen (Apel-Riemer Environmental Inc.) by using a dynamic dilution system. The systematic error on the calibration factors for those compounds is mainly determined by the uncertainty on their mixing ratio in the calibration bottle, which is $5 \%$, as stated by the manufacturer. The calibration factor for acetic acid was estimated from the experimentally determined one for acetone by taking into account the fragmentation of the nascent excited protonated molecules in the drift tube (Inomata and Tanimoto, 2010; Schwarz et al., 2009) and the ratio of the calculated collision rate constants (Su, 1994) and by assuming the same transmission efficiency for ions at $\mathrm{m} / \mathrm{z} 59$ and 61. By using a similar procedure and experimental fragmentation fractions from the literature (Demarcke et al., 2009; Warneke et al., 2003), the calibration coefficient of typical potential contributors (2-methyl-3-buten-2-ol, 1-penten-3-ol, 1-pentanal) other than isoprene to $\mathrm{m} / \mathrm{z} 69$ was found to be about $70-80 \%$ of the one of isoprene. A conservative systematic error on the calibration coefficients of acetic acid and C5 compounds other than isoprene is estimated to be 35 and $40 \%$, respectively. The accuracy on the concentration of lumped C5 compounds, based on the ion signal at $\mathrm{m} / \mathrm{z} 69$ and using the measured calibration coefficient for isoprene, is estimated to be at most $50 \%$. Calibrations as a function of relative humidity, by controlling the humidity of the zero air for diluting the calibration gas by means of a dew point generator (LI-COR LI610, Lincoln, Nebraska, USA), were performed twice in the course of the measurement period (on 3 April 2013 and 11 July 2013) and only the isoprene signal at $\mathrm{m} / \mathrm{z} 69$ was found to be humidity-dependent. A linear relationship was obtained for the isoprene calibration coefficient versus the normalized water vapour signal at $\mathrm{m} / \mathrm{z}$ $39\left(\mathrm{H}_{5}^{18} \mathrm{O}^{16} \mathrm{O}\right)$. The slope of this linear relationship, in combination with the semi-weekly calibration coefficients, was then used to infer calibration coefficients for every single measurement by considering the simultaneously measured instantaneous normalized ion signal at $\mathrm{m} / \mathrm{z}$ 39 . It should be noticed that the calibration coefficient for isoprene only varies by $15 \%$ over the range of normalized ion signals at $\mathrm{m} / \mathrm{z} 39$ obtained during the course of the experiments.

Regarding flux sign and unit convention, a positive flux indicates an emission from the field to the atmosphere and all fluxes were expressed per $\mathrm{m}^{2}$ of soil.

\subsection{Ancillary measurements}

The micro-meteorological variables relevant to this study were: air temperature $T$ (RHT2nl, Delta-T Devices Ltd, Cambridge, UK), relative humidity (RHT2nl, Delta-T Devices Ltd, Cambridge, UK), from which the saturation deficit $D_{\text {sat }}$ was calculated, global incoming radiation $R_{\mathrm{G}}$ (CNR 1, Kipp and Zonen, Delft, NL), photosynthetic photon flux density PPFD (BF3, Delta_T Devices Ltd, Cambridge, UK), rainfall (Collector and 
Tipping Bucket), soil water content at 5, 20 and $40 \mathrm{~cm}$ depth SWC (ML2, ThetaProbe, Delta-T Devices Ltd, Cambridge, UK), and friction velocity $u_{*}$, derived from the sonic anemometer. In addition, latent heat $L E$, sensible heat $H$ and net $\mathrm{CO}_{2}$ ecosystem exchange $N E E$ values were measured with the conventional eddy covariance technique (Aubinet et al., 2009). The same sonic anemometer as for the BVOC flux measurements was used for all flux measurements, and an infra-red gas analyser (IRGA, Li-7000, LI-COR, Lincoln, NE, USA) was used for water vapour concentration measurements at $20 \mathrm{~Hz}$. All these variables were averaged every half-hour.

The winter wheat phenological development was continuously monitored by taking daily pictures with a phenological camera, and by sampling winter wheat stamps at 9 dates in order to accurately determine their phenological stage and to quantify their above-ground biomass (Fig. 2). The phenological development was reported using the BBCH codification (Meier, 2001), which is a decimal scale used to describe the developmental periods of agricultural plant species. The leaf area index $L A I$ was estimated by sampling winter wheat stamps on 23 April $2013\left(0.87 \mathrm{~m}^{2} \mathrm{~m}^{-2}\right)$ and 17 June $2013\left(3.94 \mathrm{~m}^{2} \mathrm{~m}^{-2}\right)$.

The canopy conductance $g_{c}$ was estimated by inverting the PenmanMonteith equation (Pita et al., 2013) when the canopy was well established, i.e., from May 2013 to the end of the growing season. The aerodynamic resistance computation, necessary to estimate $g_{\mathrm{c}}$, is based on the parametrisations of Bonan (2008). The inversion of the Penman-Monteith equation is not suitable directly after a precipitation event, because the water vapour flux partly consists of transpiration but also includes the evaporation of water intercepted by the canopy (Granier et al., 2000). In addition, it led to very sparse results during the day-night transition hours, because both sensible heat and water vapour fluxes were close to zero at that time. Consequently, we discarded $g_{\mathrm{c}}$ when one of the following conditions was met, following Granier et al. (2000): $D_{\text {sat }}<5 \%$ of the maximal $D_{\text {sat }}$ value recorded during the growing season, $R_{\mathrm{G}}<5 \%$ of the maximal $R_{\mathrm{G}}$ value, $L E<15 \%$ of the maximal $L E$ value, $H<5 \%$ of the maximal $H$ value, rain event in the previous $2 \mathrm{~h}$. This discarded most nighttime and transition events.

\subsection{Statistical analyses}

BVOC flux composition data for each phenological stage that will be described in section 3.3 and Table 5.1 are given as flux averages, without any gap-filling of missing data. The error on the flux averages induced by individual flux random errors presented in section 2.2, was estimated by error propagation, in accordance with variance additivity properties. They will be given for each compound in Table 5 (Annex) but will not be discussed further due to their very low values.

For each phenological stage, we performed simple and multiple linear regression analyses between OVOC fluxes and environmental variables. In addition, for the temperature an exponential fit was tested (Eq (1)) by using parametrisation close to the "light-independent" parametrisation of the up-scaling BVOC model MEGAN v2.1 (Guenther et al., 2012),

$F=k_{1} \exp \left(k_{2}(T-303.15)\right)+k_{3}$

where $F$ is the flux [ug $\mathrm{m}^{-2} \mathrm{~h}^{-1}$ ], $k_{1}, k_{2}$ and $k_{3}$ are empirical coefficient [ $\mu \mathrm{g} \mathrm{m}^{-2} \mathrm{~h}^{-1}, \mathrm{~K}^{-1}$ and $\mu \mathrm{g} \mathrm{m}^{-2} \mathrm{~h}^{-1}$, respectively] and $T$ is the air temperature $[\mathrm{K}]$.

The relative contribution of the variables in multiple regression models was estimated by applying the protocol described in the "relaimpo" R-software package (Grömping, 2006).

All statistical analyses were performed on half-hourly averaged data for methanol fluxes. For the other compounds, as the exchanges were much smaller than for methanol and thus contained a large amount of random noise, the flux data were averaged per two consecutive hours prior to each analysis.

\subsection{Estimation of the OVOC fluxes with the MEGAN v2.1 algorithms}

We tested the ability of the MEGAN v2.1 model to reproduce the OVOC exchanges measured for mature leaves over three simulations. In the first simulation ('No adj.' standing for 'no adjustment of the parameters to the measured data'), we used all parameter values assigned in the model. In the second simulation ('SEF adj.'), we adjusted $S E F$ to the measured fluxes. In the third simulation ('SEF, $\beta$ and $L D F$ adj.'), we adjusted the $S E F$ and the values of $\beta$ and of the light dependent fraction $L D F$, which are key parameters in the MEGAN v2.1 model. For each simulation, we used the MEGAN v2.1 algorithms. These are described in Guenther et al. (2006), Guenther et al. (2012) and Müller et al. (2008) for the leaf age factor, the environmental factor (leaf-scale) and its scaling-up, respectively.

As the environmental factor is parametrised at the leaf scale, we built a simple canopy model to estimate the penetration of light in the canopy. For this, we divided the canopy into 8 layers of constant $L A I$, as done by Stavrakou et al. (2011). For each layer, the incident $P P F D$ was estimated from the PPFD measured at the top of the canopy, by applying Beer's law. The extinction coefficient, which represents the decrease rate for PPFD throughout the canopy, was set to 0.68 . This corresponds to the value used by Personne et al. (2009) for croplands located in North-West Europe. The fraction of sun and shade leaves was estimated by relying on the parametrisations of the MOHYCAN canopy model (Müller et al., 2008). It was also assumed that the canopy temperature was equal to the air temperature in each layer.

The canopy coefficient factor $C c e$, which is a multiplicative factor used to ensure that the estimated flux equals $S E F$ under standard conditions (Guenther et al., 2012), was estimated to 0.56 for isoprene in our canopy model, which is very close to the Cce value from the MEGAN v2.1 canopy environment model (0.57). This was adapted for each OVOC and each simulation (Table 4).

We lacked sufficient $L A I$ data to evaluate the model over the whole winter wheat growing season. Consequently, we performed the simulation only for the period when the leaves were mature (i.e., stage E). The $L A I$ was measured during that period, and as the leaves were mature we can reasonably assume that it remained constant. We thus used the algorithms described for a constant $L A I$ value in Guenther et al. (2006) to estimate the leaf age factor for mature leaves.

Finally, as senescence-induced emissions were observed for some OVOCs (Section 3.6), we estimated the leaf age factor $r_{\text {age }}$ for senescing plants. This factor was estimated as the slope of the relationship between the flux estimated when the plants were senescent (i.e., stage Sen2, Section 3.2) with all parameters derived from mature leaves (simulation 'SEF adj.') and the measured flux. By doing this, it was assumed that the $L A I$ remained constant when the plants became senescent.

\subsection{Software}

All figures and statistical analyses were performed with the Matlab 2012b software and its statistical toolbox (Mathworks, Natick, MS, USA). The parameters of the MEGAN v2.1 model were adjusted by minimising the square root difference between the modelled and the measured flux with the fminsearch and fminsearchbnd functions, where $\beta$ was constrained to be non-negative and $L D F$ to range between 0 and 1 .

\section{Results and discussion}

\subsection{Meteorological conditions}

The weather (Fig. 2) was abnormally cold in Belgium in March 2013 (Belgian Royal Meteorological Institute, RMI), due to polar wind occurrence, and the field was covered by snow from 10 to 17 March 2013 and from 24 to 26 March 2013. In April, May and June 2013, the weather was normal (RMI). July 2013 was warmer and brighter than commonly observed in Belgium (RMI), and a heat wave occurred from 
21 to 27 July 2013 (according to the RMI, a heat wave is defined by at least 5 consecutive days with a maximal temperature above $25^{\circ} \mathrm{C}$, of which at least 3 have a maximal temperature above $30^{\circ} \mathrm{C}$ ). During this event, the soil moisture at 5 and $20 \mathrm{~cm}$ depth decreased below the readily usable water threshold (estimated at $26 \%$ vol. vol $^{-1}$ ). However, the soil moisture at $40 \mathrm{~cm}$ depth remained close to the field capacity, and the latent heat flux $L E$ continued to closely follow the saturation deficit $D_{\text {sat }}$. Consequently, even though soil moisture was low near the soil surface, the winter wheat did not visibly suffer from drought stress during the whole measurement campaign.

\subsection{Winter wheat phenology}

Winter wheat was sown in autumn 2012 and germinated during that period (Fig. 1). The plants remained small with a small biomass until April 2013. The leaves unfolded in winter 2012-2013 (stage L: leaf unfolding), but, because of the cold conditions that occurred in March 2013, at the end of the growing season the stamps had one leaf less than is usually observed in this region. The tillers appeared in April (stage T: tillering), and were followed by stem elongation (stage $S$ : stem elongation). In June 2013, the reproductive phase began and the ears formed (stage E: ear formation). At the end of stage $\mathrm{E}$, the $L A I$ was estimated to $3.94 \mathrm{~m}^{2} \mathrm{~m}^{-2}$.

The leaf and stem biomass increased up to 16 July 2013. From that date, it decreased due to the start of winter wheat senescence, and the $N E E$ began to decrease. The leaves remained green overall up to 23-24 July 2013. After this the leaves, stem and ears turned progressively yellow, and by 1 August 2013 the plants were entirely dry and yellow. We thus divided the senescence period into 2 stages: the first, Sen1, occurred from 16 July to 23 July 2013, and was associated with rather green plants. The second, Sen2, occurred from 24 July 2013 to 27 July 2013 (end of the BVOC flux measurement campaign), and was associated with plants turning yellow.

The developmental stages of the winter wheat occurred under different temperature conditions, with a gradual increase in temperature from stage $\mathrm{L}$ to the senescence phase (Fig. 6). In particular, the low temperatures observed during stages $\mathrm{L}$ and $\mathrm{S}$ were not observed during the later phenological stages. Because this variable was well correlated with the OVOC fluxes investigated at LTO (Table 2), it was not possible to detect leaf age effects on OVOC exchanges. However, during the stages E (mostly mature leaves, not senescing), Sen1 (senescence mostly green plants) and Sen2 (senescence - plants turning yellow), the temperatures overlapped sufficiently to enable the detection of senescence-induced BVOC exchanges. This effect will be discussed in Section 3.6.

\subsection{BVOC fluxes in the context of other studies}

The BVOC exchange composition for the winter wheat field (Fig. 3) was in good agreement with those reported in other crop and grass studies (Bachy et al., 2016; Brilli et al., 2012; Copeland et al., 2012; Crespo et al., 2013; Custer and Schade, 2007; Eller et al., 2011; Fall et al., 1999; Graus et al., 2013; Ruuskanen et al., 2011; Warneke et al., 2002). OVOC (including methanol, acetic acid, acetaldehyde and acetone) exchanges were 22 times larger than isoprene (as a potential contributor to the $\mathrm{m} / \mathrm{z} 69$ ion signal) and monoterpene exchanges. In addition, methanol was the main exchanged compound for all stages, contributing from $33 \%$ (stage L) to $80 \%$ (other stages) to net absolute BVOC exchanges (Table 5) on a mass basis. Methanol was emitted during the whole growing season with the exception of the stage $\mathrm{L}$, which occurred under cold and mild conditions and during which it was captured.

\subsection{OVOC uptake under cold conditions}

When the weather conditions were cold and wet, i.e., during stage L, all investigated OVOCs were captured by the ecosystem. Their exchanges were on average very highly significant (Table 5), but they did not follow a clear diurnal cycle (Fig. 4), and did not correlate well with any of the tested environmental variables (Table 2).

Despite the fact that the statistical analyses did not enable us to highlight any flux driving variable(s), it is highly plausible that the uptake resulted from dry deposition and adsorption processes. Indeed, OVOCs are highly soluble in water (Sander, 2015), and the soil was wet during stage L. In addition, because of the low temperatures that occurred during that period the biological activity was very likely hindered, whereas the OVOC solubility was enhanced. It is well known that OVOC exchanges are bi-directional (Jardine et al., 2011, 2008; Kesselmeier et al., 1998; Niinemets et al., 2014; Wohlfahrt et al., 2015), and that cold and wet conditions favour uptake, whereas warm and dry conditions rather favour emission. Several studies have reported methanol (Laffineur et al., 2012; Wiß et al., 2017; Wohlfahrt et al., 2015), acetaldehyde (Jardine et al., 2008) or acetic acid uptake (Jardine et al., 2011) under wet and/or cold conditions, including at the LTO site (Bachy et al., 2016). In particular, bi-directional methanol exchanges were measured for bare soil at the LTO site, and analyses indicated that

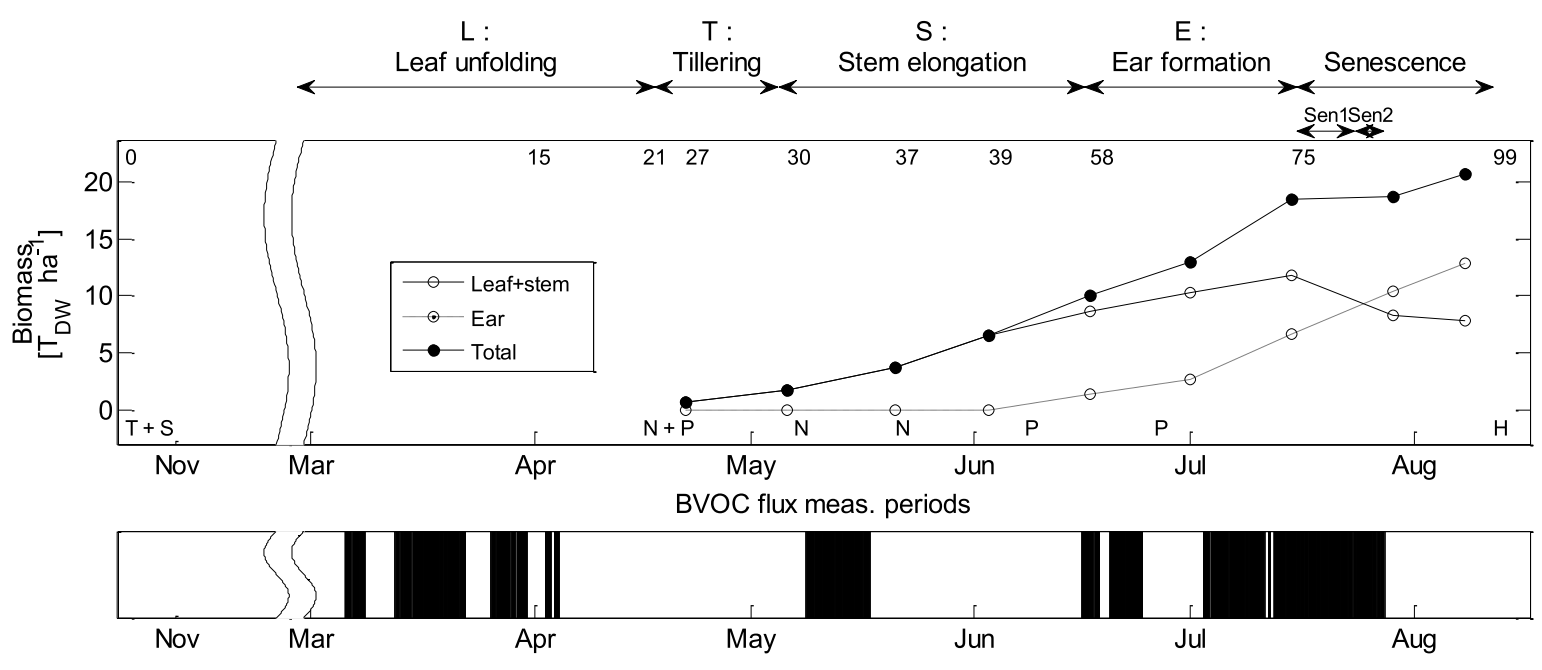

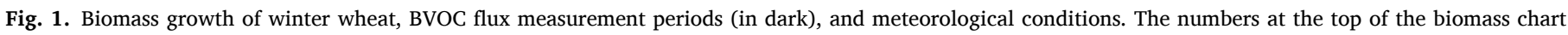

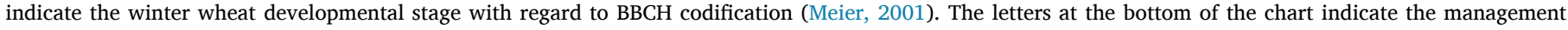
operations: $\mathrm{T}=$ tillage, $\mathrm{S}=$ sowing, $\mathrm{N}=$ nitrogen application, $\mathrm{P}=$ phytosanitary product application (weeding or fungicide), $\mathrm{H}=$ harvest. 


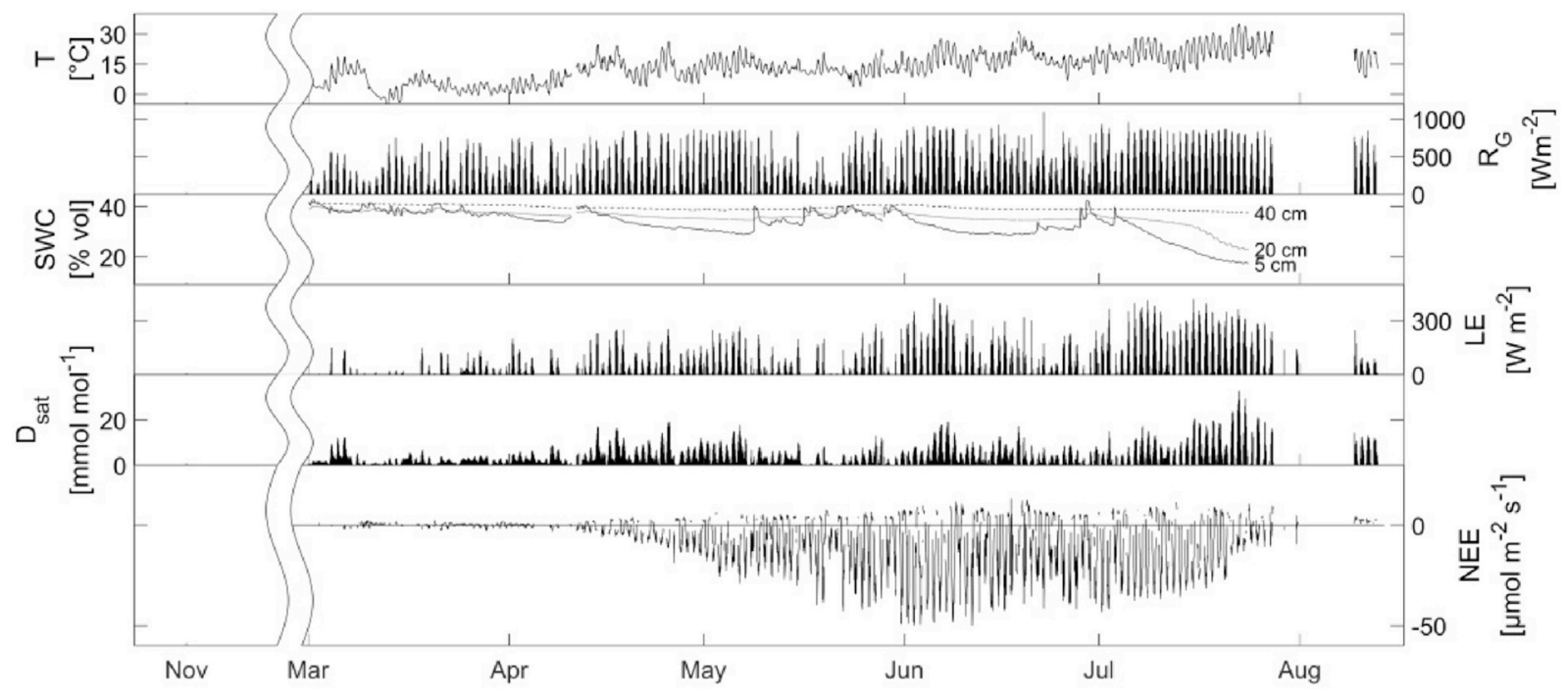

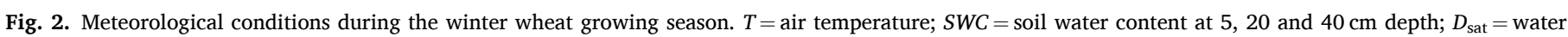
vapour saturation deficit, $R_{\mathrm{G}}=$ global incoming radiation; $L E=$ latent heat flux; $N E E=$ net ecosystem exchange.

they were driven partly by adsorption and desorption processes (Bachy et al., 2018).

\subsection{OVOC exchanges under mild and warm conditions (stages $S$ to Sen2)}

As the winter wheat developed (stages S to Sen2), the weather conditions became warmer. Methanol, acetic acid, acetaldehyde and acetone then exhibited dynamics which were in line with those reported in the literature, while $\mathrm{m} / \mathrm{z} 69$ and monoterpenes exchanges were lower and noisier, making it difficult to comment any temporal dynamics (Fig. 4, Table 2).

\subsubsection{Emission of methanol}

Methanol was mainly emitted. The fluxes followed a very clear diurnal cycle from stages $S$ to Sen2, with daytime emission and low uptake (stage $S$ ) to null exchange (other stages) during the nighttime. The methanol fluxes correlated best with incoming radiation (linear) and temperature (exponential), both variables contributing significantly to the exchange.

This dynamic is in agreement with the literature. The dependence of methanol emission on light (Fall et al., 1999; Harley et al., 2007; Mozaffar et al., 2017; Park et al., 2014; Wohlfahrt et al., 2015) and temperature (Custer and Schade, 2007; Harley et al., 2007; Karl et al., 2005; Park et al., 2014) was reported by several studies, including crop and grass studies (Custer and Schade, 2007; Fall et al., 1999; Karl et al., 2005; Mozaffar et al., 2018). As in our study, the dependence on temperature was found to be exponential at the ecosystem-scale (Crespo et al., 2013; Karl et al., 2005; Park et al., 2014), whereas the dependence on light was linear (Fall et al., 1999; Park et al., 2014; Wohlfahrt et al., 2015).

Over the course of the whole growing season, methanol emission far exceeded the uptake measured during stage L (Table 5). This implies a methanol source in the ecosystem. Because both soil (Bachy et al., 2018) and plants (Harley et al., 2007; Mozaffar et al., 2017; Niinemets and Reichstein, 2003) emit methanol under warm and light conditions, this source was probably a combination of soil and plant exchanges. Further analyses are needed to distinguish them.

\subsubsection{Uptake of acetic acid}

In contrast to the aforementioned OVOCs, acetic acid was mainly captured by the ecosystem during stages E and Sen2. The uptake was more pronounced in the morning $(06 \mathrm{~h} 00-12 \mathrm{~h} 00)$, then decreased in the afternoon $(12 \mathrm{~h} 00-18 \mathrm{~h} 00)$, reaching close to zero during the nighttime. Conversely, small but significant emissions were observed during stage $S$. The fluxes were probably too small to identify any particular diurnal dynamics during stage $S$.

Few herbaceous crop and grass studies have analysed acetic acid fluxes, but some also reported acetic acid uptake, or bidirectional exchange (Copeland et al., 2012). It has been demonstrated at the leaf-scale that some cereal species like barley or rye, which belong to the same family as winter wheat, consume acetic acid (Kesselmeier et al., 1998), whereas tree species rather emit that compound (Park et al., 2014) None of these studies investigated the relationship between acetic acid and environmental variables, though, so dynamics could not be compared.

The observed correlations were too small to definitively identify any driving variable, but the continuous captures of acetic acid during two developmental stages of the plants indicates an acetic acid sink in the ecosystem. Deposition velocities were never exceeding maximum deposition velocities, meaning that a chemical sink for that compound was not observed (Fig. 7, Annex). The uptake measured from stage E to Sen2 occurred under a low ambient acetic acid mixing ratio and warm conditions. As a consequence, it is unlikely that it resulted from purely physical dry deposition and adsorption processes, which are rather favoured by high ambient mixing ratios and low temperatures. More analyses are needed to pinpoint this sink between the plants and the soil. On one hand, if winter wheat behaves like other cereals, it consumes acetic acid (Kesselmeier et al., 1998). On the other hand, acetic acid fluxes of same magnitude as those reported in this study were observed from bare soil at LTO (Bachy et al., 2016). The occurrence of a soil sink was also suggested by Jardine et al. (2011) from acetic acid concentration gradient analyses.

\subsubsection{Emission of acetaldehyde and acetone}

The exchanges of acetaldehyde and acetone were only significant during daytime and in warm temperatures (more than $26^{\circ} \mathrm{C}$ and $22^{\circ} \mathrm{C}$, respectively). An exponential relationship was found between acetaldehyde fluxes and temperature during the stages Sen1 and Sen2, whereas acetone exchanges were rather driven by a combination of temperature and light.

These observations are quite consistent with the literature. First, several crop and grass studies conducted at the ecosystem-scale also reported small or insignificant acetaldehyde and acetone exchanges (Bachy et al., 2016; Copeland et al., 2012; Custer and Schade, 2007; Fall 
Table 2

Statistics of the regression between OVOC fluxes (half-hourly fluxes for methanol, $2 \mathrm{~h}$-averaged fluxes for other compounds) and diverse environmental variables. The upper letters indicate the phenological stage (see Fig. 1, Section 3.2 for details). The letters in the first column denote the environmental variables (Section 2.3 for details): $T$ for air temperature, $R_{\mathrm{G}}$ for global radiation, $S W C$ for soil water content, $M R$ for ambient mixing ratio, $g_{\mathrm{c}}$ for canopy conductance and $u *$ for friction velocity, The symbols indicate the slope of the relationship (when it is significant). The number of symbols gives its significance. One symbol corresponds to a p-value between 0.05 and 0.01 , two symbols to a p-value between 0.01 and 0.001 , and three symbols to a p-value below 0.001 . "ns" stands for "not significant" (p-value above 0.05 ). The numerical values are the determination coefficient (only for significant relationships). All fits were made with a linear regression model, unless "exp" is indicated. In that case the fit was made following Eq (1). "Rel. contr. of X" indicates the relative contribution of the predictor X into a multiple model (Section 2.4). The best determination coefficients are in bold.

\begin{tabular}{|c|c|c|c|c|c|c|c|c|c|c|c|c|}
\hline \multicolumn{13}{|c|}{ Methanol } \\
\hline Stage & $\mathrm{L}$ & & $\mathrm{S}$ & & $\mathrm{E}$ & & Sen1 & & Sen2 & & Whole & \\
\hline \multicolumn{13}{|c|}{ Simple regression analyses } \\
\hline$T$ & - & 0.02 & +++ & 0.08 & +++ & 0.28 & +++ & 0.59 & +++ & 0.53 & +++ & 0.33 \\
\hline$T$ (exp) & & & +++ & 0.08 & +++ & 0.31 & +++ & 0.61 & +++ & 0.53 & +++ & 0.49 \\
\hline$R_{\mathrm{G}}$ & ns & & +++ & 0.24 & +++ & 0.45 & +++ & 0.57 & +++ & 0.81 & +++ & 0.35 \\
\hline$S W C$ & ns & & ns & & - & 0.02 & - & 0.03 & ++ & 0.07 & - & 0.18 \\
\hline$M R$ & ns & & $\mathrm{ns}$ & & Ns & & ns & & - & 0.15 & +++ & 0.07 \\
\hline$g_{\mathrm{c}}$ & & & $\mathrm{ns}$ & & Ns & & - & 0.19 & ns & & - & 0.12 \\
\hline$u_{*}$ & ns & & ++ & 0.03 & +++ & 0.13 & +++ & 0.09 & +++ & 0.40 & +++ & 0.05 \\
\hline \multicolumn{13}{|c|}{ Multiple regression analyses } \\
\hline$T+R_{\mathrm{G}}$ & & & +++ & 0.25 & +++ & 0.47 & +++ & 0.69 & +++ & 0.83 & +++ & 0.47 \\
\hline Rel. contr. of $T$ & & & ns & & ++ & 0.14 & +++ & 0.35 & +++ & 0.28 & +++ & 0.22 \\
\hline Rel. contr. of $R_{\mathrm{G}}$ & & & +++ & 0.21 & +++ & 0.31 & +++ & 0.33 & +++ & 0.56 & +++ & 0.24 \\
\hline$T(\exp )+R_{\mathrm{G}}$ & & & +++ & 0.25 & +++ & 0.47 & +++ & 0.72 & +++ & 0.83 & +++ & 0.55 \\
\hline Rel. contr. of $T$ & & & ns & & +++ & 0.16 & +++ & 0.35 & +++ & 0.28 & +++ & 0.35 \\
\hline Rel. contr. of $R_{\mathrm{G}}$ & & & +++ & 0.21 & +++ & 0.31 & +++ & 0.36 & +++ & 0.56 & +++ & 0.21 \\
\hline \multicolumn{13}{|c|}{ Acetic acid } \\
\hline Stage & $\mathrm{L}$ & & $S$ & & $\mathrm{E}$ & & Sen 1 & & Sen2 & & Whole & \\
\hline \multicolumn{13}{|c|}{ Simple regression analyses } \\
\hline$T$ & ns & & ns & & - & 0.20 & ns & & ns & & - & 0.05 \\
\hline$R_{\mathrm{G}}$ & ns & & + & 0.04 & - & 0.23 & ns & & $\mathrm{ns}$ & & - & 0.06 \\
\hline$S M$ & ns & & ns & & $\mathrm{ns}$ & & ns & & ns & & +++ & 0.04 \\
\hline$M R$ & ns & & - & 0.09 & - & 0.21 & ns & & ns & & - & 0.10 \\
\hline$g_{c}$ & & & ns & & ns & & $\mathrm{ns}$ & & $\mathrm{ns}$ & & $\mathrm{ns}$ & \\
\hline$u_{*}$ & ns & & + & 0.06 & - & 0.04 & ns & & - & & ns & \\
\hline \multicolumn{13}{|c|}{ Acetaldehyde } \\
\hline Stage & $\mathrm{L}$ & & $\mathrm{S}$ & & $\mathrm{E}$ & & Sen 1 & & Sen2 & & Whole & \\
\hline \multicolumn{13}{|c|}{ Simple regression analyses } \\
\hline$T$ & ns & & ns & & ns & & +++ & 0.23 & +++ & 0.62 & +++ & 0.11 \\
\hline$T$ (exp) & & & & & & & +++ & 0.45 & +++ & 0.76 & +++ & 0.21 \\
\hline$R_{\mathrm{G}}$ & - & 0.04 & ns & & - & 0.04 & ++ & 0.09 & +++ & 0.58 & ++ & 0.01 \\
\hline$S M$ & + & 0.04 & ns & & + & 0.03 & - & 0.14 & ns & & - & 0.05 \\
\hline$M R$ & - & 0.03 & ns & & - & 0.09 & - & 0.05 & ns & & - & 0.01 \\
\hline$g_{c}$ & & & ns & & ++ & 0.12 & - & 0.19 & ns & & - & 0.03 \\
\hline$u *$ & - & 0.03 & ns & & Ns & & ns & & +++ & 0.31 & ns & \\
\hline \multicolumn{13}{|c|}{ Multiple regression analyses } \\
\hline$T+R_{\mathrm{G}}$ & & & & & & & +++ & 0.23 & +++ & 0.71 & +++ & 0.11 \\
\hline Rel. contr. of $T$ & & & & & & & +++ & 0.19 & +++ & 0.37 & +++ & 0.10 \\
\hline Rel. contr. of $R_{\mathrm{G}}$ & & & & & & & ns & & ++ & 0.33 & ns & \\
\hline$T(\exp )+R_{\mathrm{G}}$ & & & & & & & +++ & 0.45 & +++ & 0.82 & +++ & 0.23 \\
\hline Rel. contr. of $T$ & & & & & & & +++ & 0.41 & +++ & 0.50 & +++ & 0.21 \\
\hline Rel. contr. of $R_{\mathrm{G}}$ & & & & & & & ns & & ++ & 0.32 & - & 0.02 \\
\hline
\end{tabular}

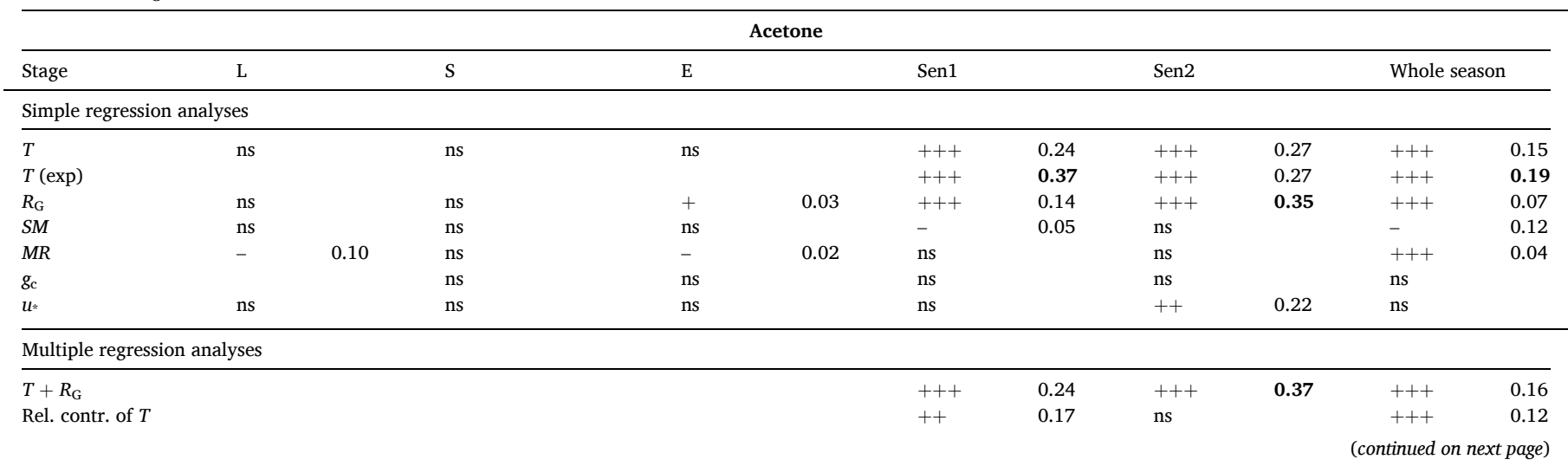




\begin{tabular}{|c|c|c|c|c|c|c|}
\hline Rel. contr. of $R_{\mathrm{G}}$ & ns & & + & 0.22 & + & 0.04 \\
\hline$T(\exp )+R_{\mathrm{G}}$ & +++ & 0.38 & +++ & 0.37 & +++ & 0.20 \\
\hline Rel. contr. of $T$ & +++ & 0.30 & ns & & +++ & 0.16 \\
\hline Rel. contr. of $R_{\mathrm{G}}$ & ns & & + & 0.22 & ns & \\
\hline
\end{tabular}
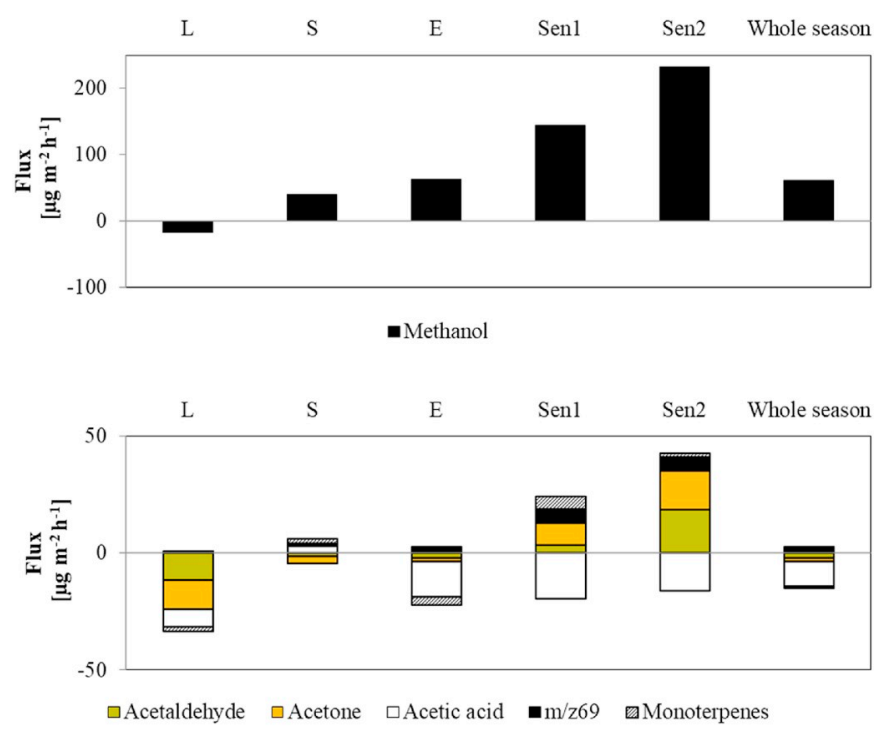

Fig. 3. Biogenic volatile organic compound (BVOC) exchange composition for each phenological stage. The phenological stages are indicated by the letters at the top (see Fig. 1 for details). The numerical values used for this chart are the flux average, without any gap-filling. They are given in Table 5 along with the standard error of the mean, the flux average significance and the relative contribution of each compound to the net absolute BVOC exchange. Note the different $y$-scales for methanol and other BVOCs.

et al., 1999; Hörtnagl et al., 2014; Ruuskanen et al., 2011). The exponential flux-temperature relationship and the diurnal flux variation are also in agreement with the literature for diverse plant species (Karl et al., 2004, 2002; Schade and Goldstein, 2001), including crops (Das et al., 2003; Karl et al., 2005).

Lastly, the emission of acetaldehyde and acetone (stages Sen 1 and Sen2) nearly outbalanced their uptake (stage L), leading to a close to zero average over the whole growing season (Table 5). Additional analyses are thus needed to conclude whether an acetaldehyde/acetone source and a sink were actually present in the ecosystem, and offset each other, or whether the exchange was only ruled by adsorption (stage L) and desorption (stages Sen1 and Sen2) processes. In addition, as bidirectional exchanges were reported from plants (Jardine et al., 2008) and soil (Bachy et al., 2016), additional analyses are needed to disentangle their relative contribution.

\subsection{Senescence-induced emissions for methanol and acetaldehyde}

The methanol emissions were, on average, significantly higher during the Sen2 stage than during the other phenological periods. The air temperature was also higher during the Sen2 stage. In order to disentangle both effects and possibly highlight a "senescence" effect on the methanol emissions, a multiple linear regression model was adjusted to the flux measured during stages E, Sen1 and Sen2. Then, the methanol flux was predicted with each model for three different global incident radiation-temperature paired values, and the predicted values were compared (Fig. 5). The choice was made to rely on a prediction model rather than directly on the flux data because the global incident radiation and temperature distribution vary between phenological stages. As a consequence, it was not possible to find global incident radiation and temperature paired values with a high occurrence for the three compared stages (i.e., stages E, Sen1 and Sen2).

The main conclusion of this analysis is that senescence-induced methanol and acetaldehyde emissions occurred when the winter wheat turned yellow and dry. The emissions of these two compounds were much higher during Sen 2 than during stages Sen 1 and E when similar temperature and/or light conditions prevailed (Fig. 5). We argue that this increase was induced by the senescing plants. Although both soil and plants probably contributed to the measured exchanges throughout the winter wheat growing season, and although it is possible that acetaldehyde exchanges were mainly driven by adsorption/ desorption processes at LTO, the hypothesis of enhanced soil emissions or desorption was implausible during the Sen2 stage because the temperature decreased from 24 to 27 July 2013, whereas the methanol and acetaldehyde emissions increased over these three days.

The senescence-induced emissions did not occur at the onset of senescence (Sen1), but when the plants became massively dry and yellow (Sen2). This finding is in line with the findings of Mozaffar et al. (2017) who observed strong increases in methanol and acetaldehyde emissions from maize leaves only a few days after the onset of the leaf chlorosis. It contrasts with the findings of Crespo et al. (2013) who reported similar emission rates for green and yellow leaves of Miscanthus spp.

Unfortunately, for technical reasons, the measurements were stopped 15 days before the winter wheat harvest so more investigation is needed to quantify the actual duration of these senescence-induced emissions. Leaf-scale experiments conducted on senescing maize leaves revealed a rise in methanol and acetaldehyde emissions that began 1-4 days after leaf chlorosis and lasted for 3-8 days (Mozaffar et al., 2017). This emission peak was followed by much smaller but still significant emissions. From our data, we can reasonably conclude that we recorded, at least partly, the rising phase of the senescence-induced emissions from 24 to 27 July.

In contrast to methanol and acetaldehyde, no senescence-induced emissions were observed for acetone and acetic acid (Fig. 5). Regarding acetone, this finding is in line with the studies of Karl et al. (2005) and Mozaffar et al. (2017) who did not report strong senescence-induced acetone emissions. However, regarding acetic acid, our finding is in contrast with these studies. It is possible that our measurement campaign was stopped too early to catch senescence-induced acetic acid emission. Mozaffar et al. (2017) observed that these emissions occurred a few days after the emission peak of methanol and acetaldehyde. At LTO, the measurements were stopped from 27 July, i.e., when methanol and acetaldehyde emissions were still increasing.

\subsection{Comparison of OVOC exchange rates with other herbaceous crops}

The average OVOC exchange rates and the maximal emission rates reported in this study were up to 3 -fold more substantial than those reported by Bachy et al. (2016) and Custer and Schade (2007) from maize and a white clover field, respectively (Table 3). The total amount of carbon emitted as measured BVOC was also 2 to 10 -fold more substantial than that reported by Miresmailli et al. (2013) for diverse crop species. In contrast, the average exchange rates reported in this study were one to two orders of magnitude lower than those reported in the only available study on winter wheat by Gonzaga Gomez et al. (2019). And exchange rates (average and maximal emission) were 2, 5, 13 and 55-fold less important than those reported by Copeland et al. (2012), by Bamberger et al. (2010), by Graus et al. (2013), and by Das et al. (2003) 

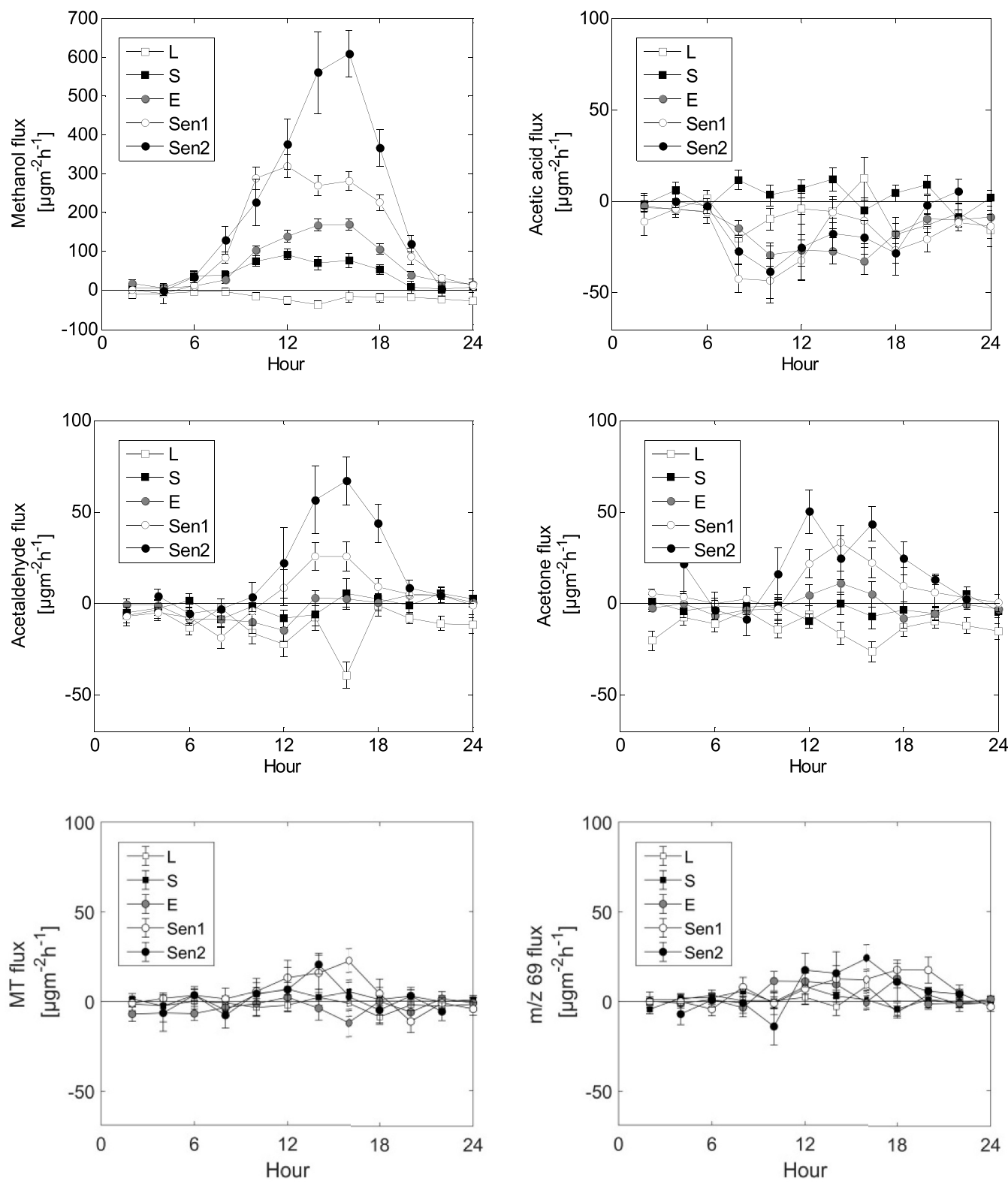

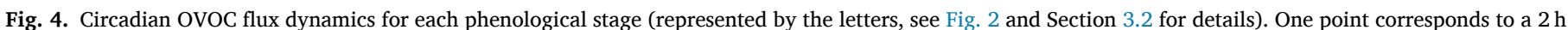
flux average $( \pm \mathrm{SE})$. Note the varying y-scales.

for Miscanthus spp, for grassland, for maize and for maize, respectively. Also, while methanol exchange rates reported in this study were more than 6-fold more substantial than in the maize study of Wiß et al. (2017), acetone and acetaldehyde exchange rates were 5 to 10 -fold less important.

Although we have limited the comparison to herbaceous crops, it is difficult to draw conclusions about the relative importance of winter wheat in OVOC exchanges by relying on that comparison. The difference with Gonzaga Gomez's values on wheat is amazing. However, when comparisons are made at the same stage of development (ripering, corresponding to our senescence phase), the disagreement is already reduced, for methanol to a factor of 4-6 for instance. The OVOC exchange rates also vary strongly within maize studies and within Miscanthus studies. Furthermore, Bachy et al. (2016) showed that OVOC fluxes strongly diverged between these three maize studies, even when they were normalized for temperature, light and phenology. Methodological limitations for each of the flux/concentration measurement techniques used are always possible. Some are identified but difficult to avoid such as poor moisture control in sampling lines/chambers, high moisture being responsible for soluble compounds dissolution, or the limited number of compounds scanned in DEC-MS. These potential technical biases add complexity to the comparison exercise. Therefore, more research, in particular long-term studies, should be conducted on these species in various climates, and to a greater extent on all major crops, in order to allow a comparison of exchange rates between crop species.

\subsection{Ability of the MEGAN v2.1 up-scaling model to reproduce the OVOC exchanges at LTO}

The MEGAN v2.1 model (Guenther et al., 2012) is designed to estimate the OVOC emissions from plants. The OVOC fluxes measured at LTO very likely originated from both soil and plants (Sections 3.4 and 3.5), but we have shown that, for all investigated OVOCs except acetic acid, the fluxes were very well correlated with temperature in an exponential way, and/or with the incident light in a linear way (Section 3.5). These two variables being the main input variables of the MEGAN v2.1 algorithms, the question arose whether MEGAN v2.1 would be able 

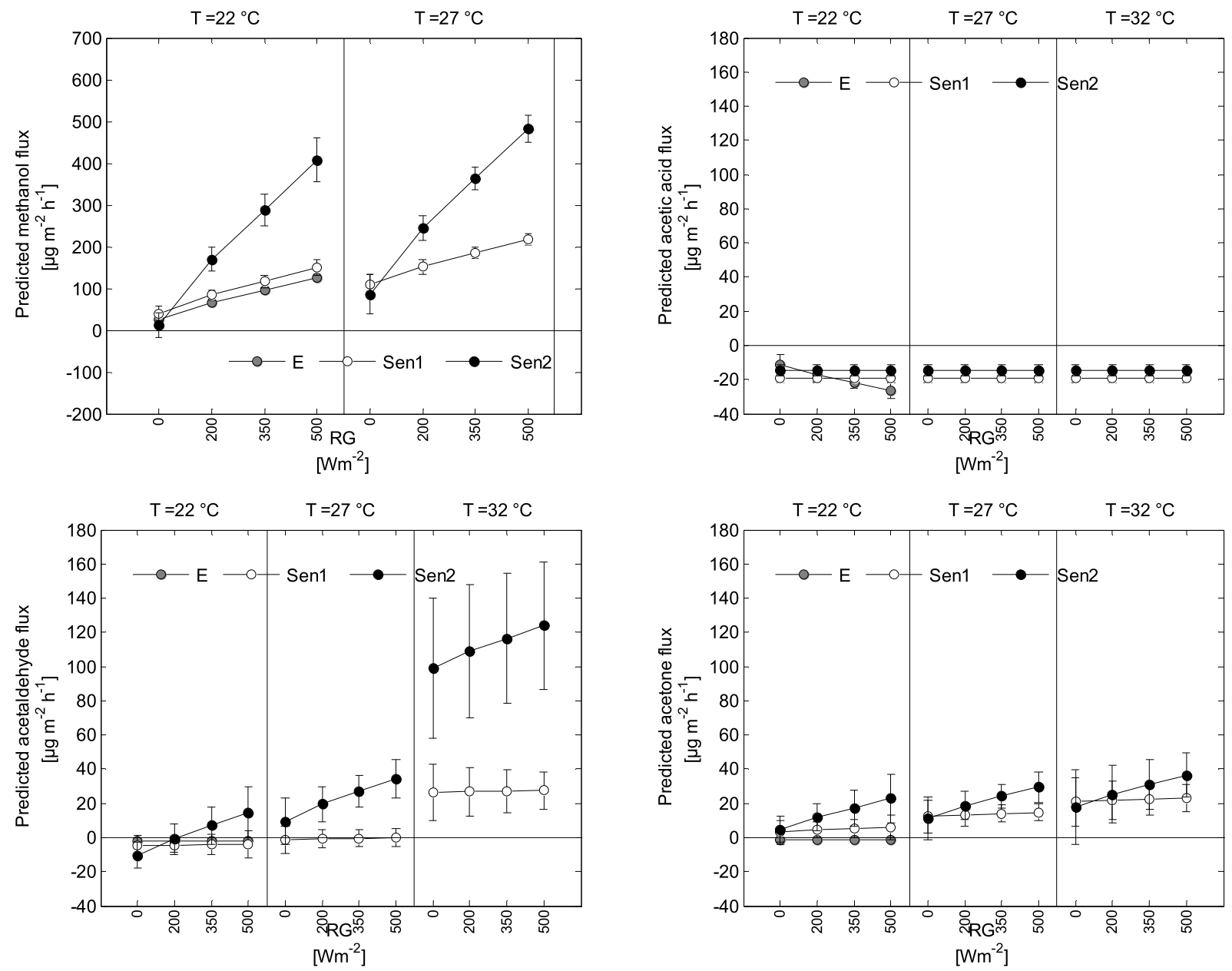

Fig. 5. OVOC fluxes under similar temperature and/or light conditions for different phenological stages (see Fig. 2 and Section 3.2 for details). Note the varying y-scales.

to reproduce the net OVOC flux observed at LTO, in spite of the fluxes not originating solely from the plants.

In order to answer that question, we performed the three simulations on mature leaves, referred as "No adj.", "SEF adj." and "SEF, $\beta$ and $L D F$ adj.", described in section 2.5. We also evaluated the ability of the model to reproduce the senescence-induced OVOC emissions in the simulation "Sen: $r_{\text {age }}$ adj.", where we estimated a leaf age factor $r_{\text {age. }}$ Methodological details are also described in Section 2.5.

The MEGAN v2.1 model was capable of reproducing the methanol fluxes measured at LTO for all selected periods, with determination coefficients of at least $75 \%$ (Table 4). It was also able to reproduce the acetaldehyde and acetone flux dynamics, but the determination coefficients were much lower than for methanol when the leaves were mature $(<20 \%)$ due to close to zero exchanges under mild conditions, characterising the mature stages E and Sen1 (Section 3.5.3). In these conditions, measured fluxes contained a large amount of random noise and therefore, although the model simulated a very small emission for both compounds, the agreement between the model and the flux was poor. Besides this, when higher temperatures were selected the agreement between the measured and the modelled acetaldehyde and acetone fluxes was much higher (Table 4).

For both compounds and all selected periods (mature - senescent), a good agreement was however found only when using adjusted values of key MEGAN parameters (simulations "SEF adj.", "SEF, $\beta$ and $L D F$ adj." and "Sen: $r_{\text {age }}$ adj.").

First, the SEF values assigned in the MEGAN v2.1 model for croplands were more than 3, 4 and 2.5 times higher than the methanol, acetaldehyde and acetone fluxes measured under standard environmental conditions, respectively. As a consequence, when adopting all parameters proposed by MEGAN v2.1, including SEF, ("No adj."), the model was qualitatively able to reproduce the exchange dynamics, but the methanol, acetaldehyde and acetone fluxes were quantitatively overestimated by these factors.

Second, the leaf age factor $r_{\text {age }}$ was adapted from 1.22 to 1.00 (values assigned in the MEGAN v2.1 model) to 2.74 and 5.60 (adjusted values) for methanol and acetaldehyde, respectively, in order for the model to reproduce the fluxes without biases. This means that the model under-estimates the effect of senescence on methanol and acetaldehyde exchanges. In addition, these adapted $r_{\text {age }}$ factors are likely underestimated because we relied on the assumption of a constant LAI throughout stages E, Sen 1 and Sen2, while it is known that active vegetative biomass starts to decrease from the beginning of Sen1 (Section 3.6).

Regarding methanol and acetone, the common adjustment of SEF, $\beta$ and $L D F$ ("SEF, $\beta$ and LDF adj." versus "SEF adj.") did not noticeably improve the quality of the fit, showing that the $\beta$ and $L D F$ assigned in the MEGAN v2.1 model were appropriate to our site, especially for methanol. In contrast, the same exercise for acetaldehyde improved the fit between measured and modelled fluxes by a factor of two. The adjusted $\beta$ value was 4.5-fold higher than the one used by the model, suggesting a steeper increase in acetaldehyde emission with temperature, and $L D F$ equalled 0 whereas a value of 0.80 is used in the MEGAN v2.1 model.

Finally, in most simulations, the intercept between the measured and the modelled flux was significantly negative. This negative intercept is 
Table 3

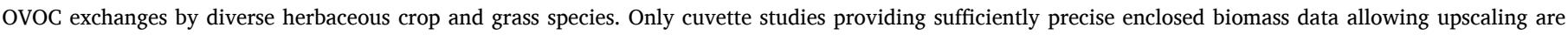

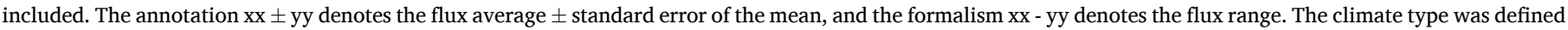

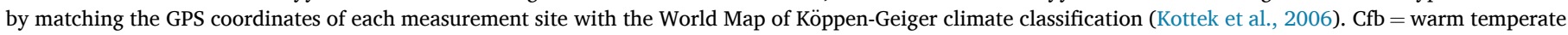
humid climate with warm summer. BSk = cold arid steppe. Dfa = humid snow climate with hot summer. Dfc $=$ humid snow climate with cool summer.

\begin{tabular}{|c|c|c|c|c|c|c|c|c|c|}
\hline \multirow[t]{2}{*}{ Species } & \multicolumn{4}{|c|}{ Flux $\left[\mu \mathrm{g} \mathrm{m}^{-2} \mathrm{~h}^{-1}\right]$} & \multicolumn{2}{|c|}{ Flux $\left[\mu \mathrm{g} \mathrm{Cm}^{-2} \mathrm{~h}^{-1}\right]$} & \multirow[b]{2}{*}{$\begin{array}{l}\text { Meas. technique/BVOC } \\
\text { conc. instr. }\end{array}$} & \multirow[b]{2}{*}{$\begin{array}{l}\text { Duration } \\
\text { (days) }\end{array}$} & \multirow[b]{2}{*}{ Authors } \\
\hline & Methanol & Acetaldehyde & Acetone & $\begin{array}{l}\text { Acetic } \\
\text { acid }\end{array}$ & $\begin{array}{l}\text { All } \\
\text { BVOC }\end{array}$ & Climate & & & \\
\hline \multirow{3}{*}{$\begin{array}{l}\text { Winter } \\
\text { wheat }\end{array}$} & $62 \pm 3.3$ & $-2 \pm 0.8$ & $-2 \pm 0.8$ & $-11 \pm 0.9$ & 21 & $\mathrm{Cfb}$ & DEC-MS/PTR-MS & 146 & This study \\
\hline & $-459-1128$ & $-148-135$ & $-135-135$ & $-261-157$ & & $\mathrm{Cfb}$ & DEC-MS/PTR-MS & 146 & This study \\
\hline & $900^{\mathrm{a}}$ & $30^{\mathrm{a}}$ & $130^{\mathrm{a}}$ & & $1500^{\mathrm{a}}$ & $\mathrm{Cfb}$ & In situ cuvette/PTR-TOF-MS & 7 & $\begin{array}{l}\text { Gonzaga } \\
\text { Gomez et al. } \\
(2019)\end{array}$ \\
\hline \multirow[t]{5}{*}{ Maize } & $27 \pm 0.8$ & $-2 \pm 0.3$ & $-0.1 \pm 0.2$ & $-5 \pm 0.2$ & 9 & $\mathrm{Cfb}$ & DEC-MS/PTR-MS & 148 & $\begin{array}{l}\text { Bachy et al. } \\
(2016)\end{array}$ \\
\hline & $3450 \pm 1456$ & & $425 \pm 223$ & & & $\mathrm{Cfb}$ & Gradient/GC-MS & 4 & $\begin{array}{l}\text { Das et al. } \\
(2003)\end{array}$ \\
\hline & $821 \pm 59^{b}$ & $159 \pm 54^{b}$ & $125 \pm 10^{\mathrm{b}}$ & $380 \pm 57^{b}$ & & BSk & In situ cuvette/PTR-MS & 2 & $\begin{array}{l}\text { Graus et al. } \\
\text { (2013) }\end{array}$ \\
\hline & $11^{\mathrm{c}}$ & $12^{\mathrm{c}}$ & $18^{c}$ & & & $\mathrm{Cfb}$ & Whole plant chamber/PTR-MS & & $\begin{array}{l}\text { Wiß et al. } \\
(2017)\end{array}$ \\
\hline & $24^{\mathrm{d}}$ & $0.39^{\mathrm{d}}$ & $1.5^{\mathrm{d}}$ & $0.09^{\mathrm{d}}$ & $30^{\mathrm{d}}$ & $\mathrm{Cfb}$ & In situ cuvette/PTR-TOF-MS & 7 & $\begin{array}{l}\text { Gonzaga } \\
\text { Gomez et al. } \\
\text { (2019) }\end{array}$ \\
\hline Rapeseed & $4696^{\mathrm{e}}$ & $60^{\mathrm{e}}$ & $208^{\mathrm{e}}$ & $60^{e}$ & $7360^{\mathrm{e}}$ & $\mathrm{Cfb}$ & In situ cuvette/PTR-TOF-MS & 7 & $\begin{array}{l}\text { Gonzaga } \\
\text { Gomez et al. } \\
\text { (2019) }\end{array}$ \\
\hline \multirow[t]{2}{*}{ Miscanthus } & $-2000-3000$ & $-1000-1000$ & $\begin{array}{l}-2000- \\
2000\end{array}$ & $-1000-500$ & & $\mathrm{Cfb}$ & DEC-MS/PTR-MS & 30 & $\begin{array}{l}\text { Copeland } \\
\text { et al. (2012) }\end{array}$ \\
\hline & & & & & $2 \pm 1$ & Dfa & Gradient/GC-MS & 5 & $\begin{array}{l}\text { Miresmailli } \\
\text { et al. (2013) }\end{array}$ \\
\hline Switchgrass & & & & & $2 \pm 1$ & Dfa & Gradient/GC-MS & 4 & $\begin{array}{l}\text { Miresmailli } \\
\text { et al. (2013) }\end{array}$ \\
\hline White clover & $-213-320$ & & & & & $\mathrm{Cfb}$ & DEC-MS/PTR-MS & 40 & $\begin{array}{l}\text { Custer and } \\
\text { Schade } \\
(2007)\end{array}$ \\
\hline \multirow[t]{3}{*}{$\begin{array}{l}\text { Mixed } \\
\text { grasses }\end{array}$} & 288 & & & & & Dfc & DEC-MS/PTR-MS & 155 & $\begin{array}{l}\text { Bamberger } \\
\text { et al. (2010) }\end{array}$ \\
\hline & $131-1073$ & & & $-41--35$ & & Dfc & EC/PTR-TOF-MS & 2 & $\begin{array}{l}\text { Ruuskanen } \\
\text { et al. (2011) }\end{array}$ \\
\hline & & & & & $5 \pm 1$ & Dfa & Gradient/GC-MS & 4 & $\begin{array}{l}\text { Miresmailli } \\
\text { et al. (2013) }\end{array}$ \\
\hline
\end{tabular}

${ }^{\mathrm{a}}$ Fluxes up-scaled with a crop dry biomass of $1000 \mathrm{~g}_{\mathrm{DW}} \mathrm{m}^{-2}$ (Gonzaga, pers. comm.).

b Fluxes up-scaled with a LAI of $6 \mathrm{~m}^{2} \mathrm{~m}^{-2}$ (Graus et al., 2013).

c Mean computed with negative fluxes set to zero although strong depositions were observed in humid conditions (Wiß et al., 2017).

${ }^{\mathrm{d}}$ Fluxes up-scaled with a crop dry biomass of $300 \mathrm{~g}_{\mathrm{DW}} \mathrm{m}^{-2}$ (Gonzaga, pers. comm.) ${ }^{\mathrm{e}}$ fluxes up-scaled with a crop dry biomass of $800 \mathrm{~g}$ DW ${ }^{-2}$ (Gonzaga, pers. comm.).

due to the fact that the MEGAN v2.1 model was built to estimate OVOC emissions (Guenther et al., 2012), whereas OVOC uptake was also measured at this site. The value of the intercept could thus be interpreted as a very basic interpretation of OVOC loss by dry deposition on the ecosystem (i.e., $L$, see (Stavrakou et al., 2011)).

\subsection{Implications for OVOC flux modelling}

Winter wheat is the most important crop grown in Europe (FAOSTATS, 2016), where it accounts for 33\% of the total harvested crop area. It is thus highly representative of the C3 agricultural lands in this region. The above analysis shows that, despite the uncertain origin (plants or soil) of the fluxes, the MEGAN v2.1 model could adequately reproduce the OVOC exchanges, but that the $S E F$ values assigned by the model were strongly over-estimated, whereas the leaf-age activity factor $\left(r_{\text {age }}\right)$ for senescing plants was strongly under-estimated for methanol and acetaldehyde. Our observations therefore suggest that the actual cropland contribution to the OVOC budget is lower than predicted by the models in Northwestern Europe, which contradicts the conclusion that agriculture significantly influences the OVOC exchanges in Benelux (Oderbolz et al., 2013).

However, because these values were determined from only one site, and because the exchanges vary greatly between sites for a single crop species, we recommend additional BVOC flux measurement studies on croplands to compare the values reported in this study. It should also be emphasised that the Cce parameter was adjusted for each OVOC in this study, in order to ensure that the exchanges equal the SEF under standard environmental conditions. In contrast, the MEGAN v2.1 model considers only one value of $\mathrm{Cce}$ for all compounds, the latest being derived from isoprene, so that the OVOC fluxes estimated with the model are not equal to $S E F$ under standard environmental conditions. The $S E F$ values reported in this study should thus be adapted accordingly when the Cce value for isoprene (i.e., 0.57) is used instead of the proper Cce value determined for each compound. The adjusted $C c e$ values being much lower than that of isoprene (Table 4), this modification would further lower the value of $S E F$, and increase the overestimation of the $S E F$ values currently assigned in the models. Note also that the $r_{\text {age }}$ values proposed in this study were estimated by considering a $L A I$ equal to that of a mature plant. They should be adapted accordingly if the vegetation model simulates a decrease in $L A I$ along with the (vegetative part of the) plant senescence.

Regarding acetaldehyde, the ability of the model to reproduce these exchanges was strongly improved when the parameters $\beta$ and $L D F$ were adjusted. Nevertheless, given the low model performance for mature 
Table 4

Parameters used in each simulation (Section 2.5) of the MEGAN v2.1 model and statistics of the relationship between modelled (x) and measured (y) OVOC flux. The confidence intervals (CI) were estimated with an alpha value of $5 \%$.

\begin{tabular}{|c|c|c|c|c|}
\hline & No adj. & SEF adj. & $\begin{array}{l}S E F, \beta \text { and } L D F \\
\text { adj. }\end{array}$ & Sen: $r_{\text {age }}$ adj. \\
\hline \multicolumn{5}{|l|}{ Methanol } \\
\hline SEF & $900^{\mathrm{a}}$ & $252^{\mathrm{b}}$ & $199^{c}$ & $252^{c}$ \\
\hline$\beta$ & $0.080^{\mathrm{a}}$ & $0.080^{\mathrm{a}}$ & $0.082^{c}$ & $0.080^{c}$ \\
\hline$L D F$ & $0.80^{\mathrm{a}}$ & $0.80^{\mathrm{a}}$ & $0.93^{c}$ & $0.80^{c}$ \\
\hline$r_{\text {age }}$ & $1.02^{\mathrm{a}}$ & $1.02^{\mathrm{a}}$ & $1.02^{\mathrm{a}}$ & $2.74^{\mathrm{d}}$ \\
\hline Cce & 0.31 & 0.31 & 0.42 & 0.31 \\
\hline Slope $( \pm \mathrm{CI})$ & $\begin{array}{l}0.28 \\
(0.26-0.30)\end{array}$ & $\begin{array}{l}1.00 \\
(0.94-1.07)\end{array}$ & $\begin{array}{l}1.00 \\
(0.94-1.06)\end{array}$ & $\begin{array}{l}1.00 \\
(0.87-1.13)\end{array}$ \\
\hline $\begin{array}{l}\text { Intercept } \\
\quad( \pm \mathrm{CI})\end{array}$ & $\begin{array}{l}-30(-39-- \\
20)\end{array}$ & $\begin{array}{l}-30(-39- \\
20)\end{array}$ & $0(-8-8)$ & $\begin{array}{l}-162(-224- \\
-100)\end{array}$ \\
\hline $\mathrm{R}^{2}$ & 0.75 & 0.75 & 0.76 & 0.85 \\
\hline RMSE & 55 & 55 & 54 & 108 \\
\hline \multicolumn{5}{|l|}{ Acetaldehyde } \\
\hline SEF & $80^{\mathrm{a}}$ & $19^{\mathrm{b}}$ & $9^{c}$ & $19^{c}$ \\
\hline$\beta$ & $0.130^{\mathrm{a}}$ & $0.130^{\mathrm{a}}$ & $0.592^{c}$ & $0.130^{c}$ \\
\hline$L D F$ & $0.80^{\mathrm{a}}$ & $0.80^{\mathrm{a}}$ & $0^{c}$ & $0.80^{c}$ \\
\hline$r_{\mathrm{age}}$ & $1.00^{\mathrm{a}}$ & $1.00^{\mathrm{a}}$ & $1.00^{\mathrm{a}}$ & $5.60^{\mathrm{d}}$ \\
\hline Cce & 0.27 & 0.27 & 0.01 & 0.27 \\
\hline Slope $( \pm \mathrm{CI})$ & $\begin{array}{l}0.24 \\
(0.15-0.33)\end{array}$ & $\begin{array}{l}1.02 \\
(0.64-1.39)\end{array}$ & $\begin{array}{l}1.07 \\
(0.82-1.33)\end{array}$ & $\begin{array}{l}1.00 \\
(0.85-1.15)\end{array}$ \\
\hline $\begin{array}{l}\text { Intercept } \\
\quad( \pm \mathrm{CI})\end{array}$ & $-7(-10--3)$ & $-7(-10--3)$ & $-3(-5--1)$ & $\begin{array}{l}-26(-35-- \\
18)\end{array}$ \\
\hline $\mathrm{R}^{2}$ & 0.09 & $0.09 / 0.36^{\mathrm{e}}$ & $0.19 / 0.44^{\mathrm{e}}$ & 0.81 \\
\hline RMSE & 21 & 21 & 20 & 17 \\
\hline \multicolumn{5}{|l|}{ Acetone } \\
\hline SEF & $80^{\mathrm{a}}$ & $31^{\mathrm{b}}$ & $15^{c}$ & \\
\hline$\beta$ & $0.10^{\mathrm{a}}$ & $0.10^{\mathrm{a}}$ & $0.36^{\mathrm{c}}$ & \\
\hline$L D F$ & $0.20^{\mathrm{a}}$ & $0.20^{\mathrm{a}}$ & $0.03^{c}$ & \\
\hline$r_{\mathrm{age}}$ & $1.00^{\mathrm{a}}$ & $1.00^{\mathrm{a}}$ & $1.00^{\mathrm{a}}$ & \\
\hline $\mathrm{Cce}$ & 0.13 & 0.13 & 0.02 & \\
\hline Slope $( \pm \mathrm{CI})$ & $\begin{array}{l}0.39 \\
(0.27-0.52)\end{array}$ & $\begin{array}{l}1.02 \\
(0.70-1.33)\end{array}$ & $\begin{array}{l}1.06 \\
(0.78-1.34)\end{array}$ & \\
\hline $\begin{array}{l}\text { Intercept } \\
\quad( \pm \mathrm{CI})\end{array}$ & $\begin{array}{l}-10(-15-- \\
6)\end{array}$ & $\begin{array}{l}-10(-15-- \\
6)\end{array}$ & $-1(-4-1)$ & \\
\hline $\mathrm{R}^{2}$ & 0.11 & $0.11 / 0.27^{\mathrm{e}}$ & $0.15 / 0.24^{\mathrm{e}}$ & \\
\hline RMSE & 19 & 19 & 19 & \\
\hline
\end{tabular}

a Taken from Guenther et al. (2012) and Guenther et al. (2006) for PFT 15 and mature leaves.

b Value estimated by multiplying the SEF taken from Guenther et al. (2012) by the slope of the simulation "No adj."

c Parameters adjusted with the OVOC flux data measured during stages E and Sen1.

d Parameters adjusted with the OVOC flux data measured during stage Sen2.

e Left: comparison made by taking all data of the stages E and Sen1. Right: comparison made by taking data above $26^{\circ} \mathrm{C}$ during these periods.

leaves (low $\mathrm{R}^{2}$ ), we recommend more accurate acetaldehyde flux measurements in order to better constrain the MEGAN parameters. For that purpose, PTR-TOF-MS instruments, which allow the measurement of BVOC fluxes by direct eddy covariance instead of DEC-MS, resulting in more accurate fluxes, could be used.

Finally, the MEGAN v2.1 model was clearly not appropriate for reproducing the exchanges of acetic acid from the winter wheat field, because this compound was mainly captured by the ecosystem whereas MEGAN v2.1 is designed to simulate emissions.

\section{Conclusion}

We present the first BVOC flux study conducted at the ecosystemscale in a winter wheat field and which encompassed most developmental stages of the plants. This study investigated several BVOCs, and focused mainly on OVOC exchanges.

Overall, the BVOC exchange composition and the OVOC exchange dynamics were well in line with those reported for croplands and grasslands, with methanol being the main compound emitted. With the exception of acetic acid, the OVOC exchanges were bi-directional with uptakes under cold and wet conditions, and emissions under warmer and drier conditions. These exchanges correlated well with temperature (exponential) and light (linear), with the relative importance of these two variables varying between compounds. The exchanges likely originated from both the soil and the plants, so more analyses are needed to better define the origin of the fluxes. For that purpose, the use of in situ chambers located on the soil and over a whole plant could be used.

Despite the mixed origin of the fluxes, the MEGAN v2.1 model was able to reproduce the exchanges of methanol, acetaldehyde and acetone during the mature phase of the plants, given a strong adaptation of the standard emission factor SEF. In contrast, when the currently assigned $S E F$ s were used, the OVOC exchanges were strongly over-estimated. In this study, we determined $S E F$ values for these three compounds. Since the adjusted $S E F$ values are much lower than those currently assigned in MEGAN, the contribution of croplands to the OVOC budget in this region will be lowered if our values are actually extrapolable to the North-West region. However, given the large variability in OVOC exchange rates for a single crop species, and the absence of other BVOC studies on winter wheat in this region to evaluate our results, our estimated SEF should be validated for this region. In addition, these results are probably not applicable to other regions. Definitely, more BVOC flux measurement studies on diverse crop species and sites are needed to better determine the exchange rates and compare the crop species.

Thirdly, significant senescence-induced emissions were reported for methanol and acetaldehyde when the leaves were turning yellow. However, no senescence effect was noticed when the plants were still green. These senescence-induced emissions could be reproduced by MEGAN v2.1, given a strong increase in the leaf age factor for this phenological phase. This adjustment could also be generalised for C3 crops grown in North-West Europe, but more studies are required to validate this. In addition, because the senescence-induced emissions are susceptible to high variations throughout the senescence period, the OVOC exchange dynamics should be investigated during the whole senescing phase in order to better characterise the leaf age factors throughout this phase.

Finally, in contrast to the other investigated OVOCs, acetic acid was mainly captured by the ecosystem over the whole growing season, including during warm and dry periods. As a consequence, the MEGAN v2.1 model, which is designed to simulate BVOC emissions, was unable to reproduce the exchanges for acetic acid. The few other studies which have investigated acetic acid also reported uptake by the ecosystem. As a consequence this feature is probably not site-specific but might be general to agricultural lands, although more flux measurement studies should been carried out on this compound in order to evaluate to what extent our observations are generalisable. In addition, the model assumes that acetaldehyde and acetic acid follow similar dynamics, and groups these two compounds as "bidirectional VOC" (Guenther et al., 2012). Our results however clearly showed that acetic acid and acetaldehyde follow distinct dynamics, and that they should be distinguished. As a consequence, caution is needed when estimating acetic acid fluxes for croplands with the MEGAN v2.1 model.

\section{Funding}

This work was supported by the FRS-FNRS, Belgium [A215-MCF/ DM-A362 FC 95918, CROSTVOC project T.0086.13]. LTO maintenance was carried out within the framework of the ICOS Wallonia project, which was supported by the Service Public de Wallonie, Belgium [1217769].

\section{Declaration of competing interest}

The authors declare that they have no known competing financial interests or personal relationships that could have appeared to influence the work reported in this paper. 


\section{Acknowledgements}

The authors wish to thank Henri Chopin, Alain Debacq and Frédéric
Wilmus for the BVOC equipment installation and station monitoring, the farmer Philippe Van Eyck, and the Lonzée ICOS team for site follow-up and measurement of environmental parameters.

\section{Appendix A. Supplementary data}

Supplementary data to this article can be found online at https://doi.org/10.1016/j.atmosenv.2019.117105.

\section{Appendix}

\subsection{BVOC composition per phenological stage}

Table 5

BVOC flux ( $\mu \mathrm{g} \mathrm{m}^{-2} \mathrm{~h}^{-1}$ ) average ( \pm SE), significance (sign.) and contribution ('\% contr.') to the net absolute average exchange for each phenological stage of winter wheat growth. The last additional line in the "whole season" group is the error of the flux averages induced by individual flux random errors, in the same units as the flux. The letters in the first column indicate the phenological stages (Fig. 2, Section 3.2 for details). The symbols indicate the p-value of the Student's $t$-test of the measured flux average against $0 \mu \mathrm{g} \mathrm{m}^{-2} \mathrm{~h}^{-1}$. One symbol corresponds to a p-value between 0.05 and 0.01 , two symbols to a p-value between 0.01 and 0.001 , and three symbols to a p-value below 0.001. "ns" stands for "not significant" (p-value above 0.05). No gap-filling was applied prior to flux averaging.

\begin{tabular}{|c|c|c|c|c|c|c|}
\hline & Methanol & Acetaldehyde & Acetone & Acetic acid & $\mathrm{m} / \mathrm{z} 69$ & Monoterpenes \\
\hline \multirow[t]{3}{*}{$\mathrm{L}$} & $-17.2 \pm 2.7$ & $-11.6 \pm 1.6$ & $-12.4 \pm 1.4$ & $-7.7 \pm 2.1$ & $0.8 \pm 1.1$ & $-2.0 \pm 1.1$ \\
\hline & $* * *$ & & $* * *$ & & Ns & Ns \\
\hline & $33 \%$ & $22 \%$ & $24 \%$ & $15 \%$ & $1 \%$ & $4 \%$ \\
\hline \multirow[t]{3}{*}{$\mathrm{S}$} & $40.9 \pm 4.2$ & $-1.6 \pm 1.4$ & $-2.8 \pm 1.3$ & $3.1 \pm 1.5$ & $1.2 \pm 1.0$ & $1.7 \pm 1.2$ \\
\hline & $* * *$ & ns & $*$ & $*$ & Ns & Ns \\
\hline & $80 \%$ & $3 \%$ & $6 \%$ & $6 \%$ & $2 \%$ & $3 \%$ \\
\hline \multirow[t]{3}{*}{ E } & $63.5 \pm 4.0$ & $-2.4 \pm 1.1$ & $-1.3 \pm 1.3$ & $-15.1 \pm 1.5$ & $2.9 \pm 1.0$ & $-3.6 \pm 1.6$ \\
\hline & $* * *$ & $*$ & Ns & $* * *$ & $* *$ & $*$ \\
\hline & $72 \%$ & $3 \%$ & $1 \%$ & $17 \%$ & $3 \%$ & $4 \%$ \\
\hline \multirow[t]{3}{*}{ Sen1 } & $144.5 \pm 10.2$ & $3.5 \pm 2.0$ & $9.4 \pm 2.2$ & $-19.6 \pm 2.6$ & $6.1 \pm 1.7$ & $5.3 \pm 2.1$ \\
\hline & $* * *$ & ns & $* * *$ & $* * *$ & $* * *$ & $*$ \\
\hline & $80 \%$ & $2 \%$ & $5 \%$ & $10 \%$ & $3 \%$ & $3 \%$ \\
\hline \multirow[t]{3}{*}{ Sen2 } & $232.5 \pm 27.3$ & $18.6 \pm 4.1$ & $16.4 \pm 3.3$ & $-16.1 \pm 3.2$ & $6.3 \pm 2.5$ & $1.4 \pm 2.2$ \\
\hline & $* * *$ & $* * *$ & $* * *$ & $* * *$ & $*$ & Ns \\
\hline & $80 \%$ & $6 \%$ & $6 \%$ & $6 \%$ & $2 \%$ & $0 \%$ \\
\hline \multirow[t]{4}{*}{ Whole season } & $62.2 \pm 3.3$ & $-2.3 \pm 0.8$ & $-1.5 \pm 0.8$ & $-10.6 \pm 0.9$ & $2.8 \pm 0.6$ & $-0.5 \pm 0.7$ \\
\hline & $* * *$ & $* *$ & $*$ & $* * *$ & $* * *$ & Ns \\
\hline & $78 \%$ & $3 \%$ & $2 \%$ & $13 \%$ & $3 \%$ & $1 \%$ \\
\hline & 1.2 & 0.4 & 0.3 & 0.3 & 0.2 & 0.1 \\
\hline
\end{tabular}

\subsection{Temperature and global radiation distribution per phenological stage}
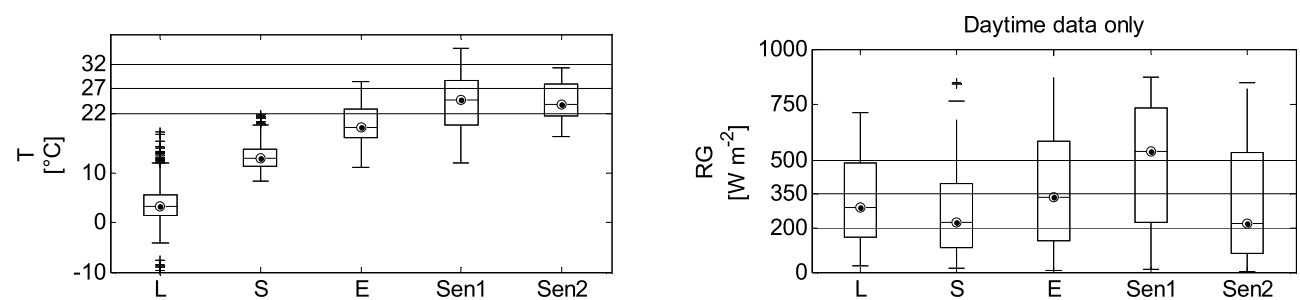

Fig. 6. Boxplot of air temperature $T$ and global incoming radiation $R_{\mathrm{G}}$ for each phenological stage in the growth of winter wheat. One box represents one phenological stage, indicated by the letters at the bottom (see Fig. 2, Section 3.2 for details). Description of the box: the middle line with the dot is the median; the lower and upper edges are the 1st and 3rd quartiles, respectively. The whiskers correspond to 1.5 -fold the interquartile interval, and the crosses to the outliers. The boxplot distribution was performed only with $T$ and $R_{\mathrm{G}}$ data measured when a valid methanol flux was available. The dotted lines indicate the respective values of $T$ and $R_{\mathrm{G}}$ taken to make the OVOC flux comparison between phenological stages in Fig. 5 ..

\subsection{Acetic acid deposition velocities per phenological stage}



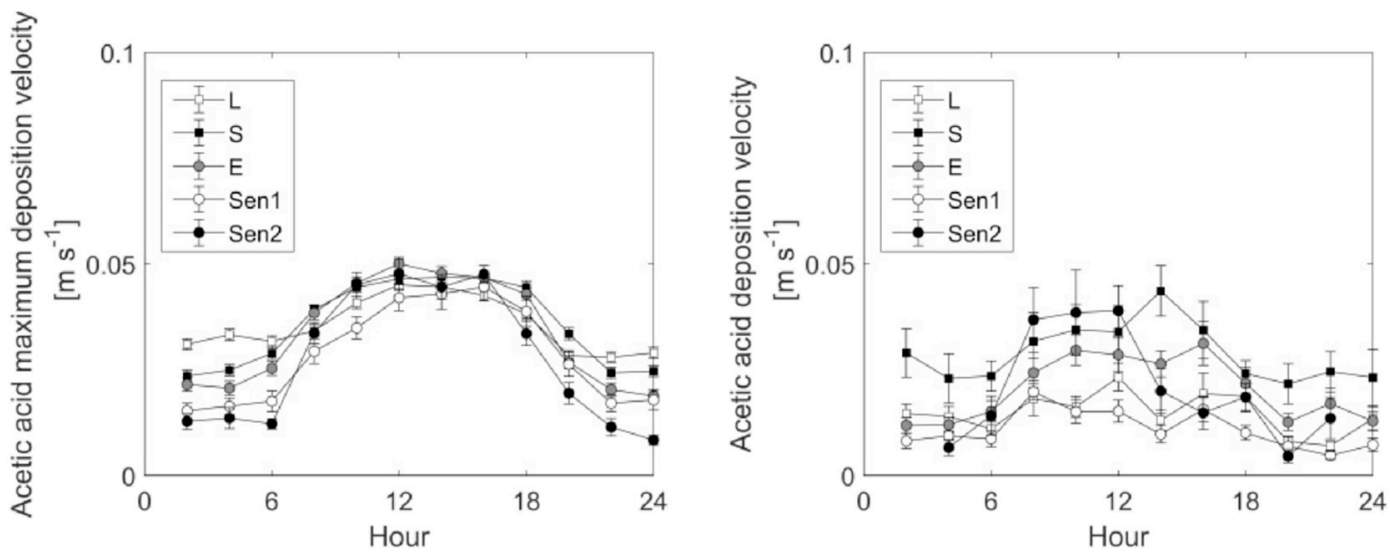

Fig. 7. Circadian maximum and acetic acid deposition velocity dynamics for each phenological stage (represented by the letters, see Fig. 2 and Section 3.2 for details). One point corresponds to a $2 \mathrm{~h}$ flux average ( $\pm \mathrm{SE})$.

\subsection{Additional statistics of the regression between OVOC fluxes and diverse environmental variables}

Table 6

Number of points for the simple linear regressions between OVOC fluxes (half-hourly fluxes for methanol, 2h-averaged fluxes for other compounds) and diverse environmental variables. Same naming conventions as Table 2 for phenological stages and environmental variables.

\begin{tabular}{lllllll}
\hline \multicolumn{7}{c}{ Methanol } \\
\hline Stage & $\mathrm{L}$ & $\mathrm{S}$ & $\mathrm{E}$ & Sen1 & Sen2 & Whole season \\
\hline$T$ & 395 & 316 & 584 & 246 & 100 & 1641 \\
$R_{\mathrm{G}}$ & 395 & 293 & 583 & 242 & 100 & 1613 \\
$S W C$ & 395 & 316 & 585 & 246 & 100 & 1642 \\
$M R$ & 395 & 316 & 587 & 247 & 100 & 1645 \\
$g_{\mathrm{c}}$ & - & 24 & 130 & 94 & 22 & 270 \\
$u_{*}$ & 395 & & 587 & 247 & 100 & 1645 \\
$S_{\text {Stage }}$ & $\mathrm{L}$ & $\mathrm{S}$ & Acetic acid/Acetaldehyde/Acetone & Sen2 & Whole season \\
$T$ & 133 & 108 & 206 & 85 & 40 & 574 \\
$R_{\mathrm{G}}$ & 133 & 102 & 206 & 85 & 40 & 568 \\
$S W C$ & 133 & 108 & 206 & 85 & 40 & 574 \\
$M R$ & 133 & 108 & 206 & 85 & 40 & 574 \\
$g_{\mathrm{c}}$ & - & 16 & 59 & 40 & 45 & 57 \\
$u_{*}$ & 133 & 108 & 206 & 85 & 40 & 574 \\
\hline
\end{tabular}

\section{References}

Ammann, C., Brunner, A., Spirig, C., Neftel, A., 2006. Technical note: water vapour concentration and flux measurements with PTR-MS. Atmos. Chem. Phys. 6, 4643-4651. https://doi.org/10.5194/acp-6-4643-2006.

Aubinet, M., Moureaux, C., Bodson, B., Dufranne, D., Heinesch, B., Suleau, M., Vancutsem, F., Vilret, A., 2009. Carbon sequestration by a crop over a 4-year sugar beet/winter wheat/seed potato/winter wheat rotation cycle. Agric. For. Meteorol. https://doi.org/10.1016/j.agrformet.2008.09.003.

Bachy, A., Aubinet, M., Amelynck, C., Schoon, N., Bodson, B., Moureaux, C., Delaplace, P., De Ligne, A., Heinesch, B., 2018. Methanol exchange dynamics between a temperate cropland soil and the atmosphere. Atmos. Environ. 176, 229-239. https://doi.org/10.1016/j.atmosenv.2017.12.016.

Bachy, A., Aubinet, M., Schoon, N., Amelynck, C., Bodson, B., Moureaux, C., Heinesch, B., 2016. Are BVOC exchanges in agricultural ecosystems overestimated? Insights from fluxes measured in a maize field over a whole growing season. Atmos. Chem. Phys. 16, 5343-5356. https://doi.org/10.5194/acp-16-5343-2016.

Bamberger, I., Hörtnagl, L., Schnitzhofer, R., Graus, M., Ruuskanen, T.M., Müller, M. Dunkl, J., Wohlfahrt, G., Hansel, A., 2010. BVOC fluxes above mountain grassland. Biogeosciences. https://doi.org/10.5194/bg-7-1413-2010.

Bonan, G., 2008. Ecological Climatology: Concepts and Equations, second ed. Cambridge University Press, United-Kingdom.

Brilli, F., Gioli, B., Zona, D., Pallozzi, E., Zenone, T., Fratini, G., Calfapietra, C., Loreto, F., Janssens, I.A., Ceulemans, R., 2014. Simultaneous leaf- and ecosystem-level fluxes of volatile organic compounds from a poplar-based SRC plantation. Agric. For. Meteorol. 187, 22-35.

Brilli, F., Hörtnagl, L., Bamberger, I., Schnitzhofer, R., Ruuskanen, T.M., Hansel, A., Loreto, F., Wohlfahrt, G., 2012. Qualitative and quantitative characterization of volatile organic compound emissions from cut grass. Environ. Sci. Technol. https:// doi.org/10.1021/es204025y.
Copeland, N., Cape, J.N., Heal, M.R., 2012. Volatile organic compound emissions from Miscanthus and short rotation coppice willow bioenergy crops. Atmos. Environ. https://doi.org/10.1016/j.atmosenv.2012.06.065.

Crespo, E., Graus, M., Gilman, J.B., Lerner, B.M., Fall, R., Harren, F.J.M., Warneke, C., 2013. Volatile organic compound emissions from elephant grass and bamboo cultivars used as potential bioethanol crop. Atmos. Environ. https://doi.org/ 10.1016/j.atmosenv. 2012.10.009.

Custer, T., Schade, G., 2007. Methanol and acetaldehyde fluxes over ryegrass. Tellus Ser. B Chem. Phys. Meteorol. 59, 673-684.

Das, M., Kang, D.W., Aneja, V.P., Lonneman, W., Cook, D.R., Wesely, M.L., 2003. Measurements of hydrocarbon air-surface exchange rates over maize. Atmos. Environ. 37, 2269-2277. https://doi.org/10.1016/s1352-2310(03)00076-1.

Demarcke, M., Amelynck, C., Schoon, N., Dhooghe, F., Van Langenhove, H., Dewulf, J., 2009. Laboratory studies in support of the detection of sesquiterpenes by protontransfer-reaction-mass-spectrometry. Int. J. Mass Spectrom. 279, 156-162. https:// doi.org/10.1016/j.ijms.2008.10.023.

Eller, A.S.D., Sekimoto, K., Gilman, J.B., Kuster, W.C., de Gouw, J.A., Monson, R.K., Graus, M., Crespo, E., Warneke, C., Fall, R., 2011. Volatile organic compound emissions from switchgrass cultivars used as biofuel crops. Atmos. Environ. https:// doi.org/10.1016/j.atmosenv.2011.03.042.

Fall, R., Karl, T., Hansel, A., Jordan, A., Lindinger, W., 1999. Volatile organic compounds emitted after leaf wounding: on-line analysis by proton-transfer-reaction mass spectrometry. J. Geophys. Res. Atmos. 104, 15963-15974. https://doi.org/10.1029/ 1999JD900144.

Fowler, D., Pilegaard, K., Sutton, M.A., Ambus, P., Raivonen, M., Duyzer, J., Simpson, D., Fagerli, H., Fuzzi, S., Schjoerring, J.K., Granier, C., Neftel, A., Isaksen, I.S.A., Laj, P., Maione, M., Monks, P.S., Burkhardt, J., Daemmgen, U., Neirynck, J., Personne, E., Wichink-Kruit, R., Butterbach-Bahl, K., Flechard, C., Tuovinen, J.P., Coyle, M., Gerosa, G., Loubet, B., Altimir, N., Gruenhage, L., Ammann, C., Cieslik, S., Paoletti, E., Mikkelsen, T.N., Ro-Poulsen, H., Cellier, P., Cape, J.N., Horváth, L., Loreto, F., Niinemets, Ü., Palmer, P.I., Rinne, J., Misztal, P., Nemitz, E., Nilsson, D., 
Pryor, S., Gallagher, M.W., Vesala, T., Skiba, U., Brüggemann, N., Zechmeister Boltenstern, S., Williams, J., O'Dowd, C., Facchini, M.C., de Leeuw, G., Flossman, A. Chaumerliac, N., Erisman, J.W., 2009. Atmospheric composition change: ecosystems-Atmosphere interactions. Atmos. Environ. https://doi.org/10.1016/j. atmosenv.2009.07.068.

Fry, M.M., Naik, V., West, J.J., Schwarzkopf, M.D., Fiore, A.M., Collins, W.J., Dentener, F.J., Shindell, D.T., Atherton, C., Bergmann, D., Duncan, B.N., Hess, P., MacKenzie, I.A., Marmer, E., Schultz, M.G., Szopa, S., Wild, O., Zeng, G., 2012. The influence of ozone precursor emissions from four world regions on tropospheric composition and radiative climate forcing. J. Geophys. Res. Atmos. 117, D07306. https://doi.org/10.1029/2011JD017134.

Gallagher, M.W., Clayborough, R., Beswick, K.M., Hewitt, C.N., Owen, S., Moncrieff, J., Pilegaard, K., 2000. Assessment of a relaxed eddy accumulation for measurements of fluxes of biogenic volatile organic compounds: study over arable crops and a mature beech forest. Atmos. Environ. https://doi.org/10.1016/S1352-2310(00)00066-2.

Gonzaga Gomez, L., Loubet, B., Lafouge, F., Ciuraru, R., Buysse, P., Durand, B., Gueudet, J.-C., Fanucci, O., Fortineau, A., Zurfluh, O., Decuq, C., Kammer, J., Duprix, P., Bsaibes, S., Truong, F., Gros, V., Boissard, C., 2019. Comparative study of biogenic volatile organic compounds fluxes by wheat, maize and rapeseed with dynamic chambers over a short period in northern France. Atmos. Environ. https:// doi.org/10.1016/j.atmosenv.2019.116855.

Granier, A., Loustau, D., Bréda, N., 2000. A generic model of forest canopy conductance dependent on climate, soil water availability and leaf area index. Ann. For. Sci. 57, 755-765.

Graus, M., Eller, A.S.D., Fall, R., Yuan, B., Qian, Y., Westra, P., de Gouw, J., Warneke, C., 2013. Biosphere-atmosphere exchange of volatile organic compounds over C4 biofuel crops. Atmos. Environ. https://doi.org/10.1016/j.atmosenv.2011.12.042.

Grömping, U., 2006. Relative importance for linear regression in $R$ : the package relaimpo. J. Stat. Softw. https://doi.org/10.18637/jss.v017.i01.

Guenther, A., Karl, T., Harley, P., Wiedinmyer, C., Palmer, P.I., Geron, C., 2006. Estimates of global terrestrial isoprene emissions using MEGAN (model of emissions of gases and aerosols from nature). Atmos. Chem. Phys. 6, 3181-3210.

Guenther, A.B., Jiang, X., Heald, C.L., Sakulyanontvittaya, T., Duhl, T., Emmons, L.K., Wang, X., 2012. The model of emissions of gases and aerosols from nature version 2.1 (MEGAN2.1): an extended and updated framework for modeling biogenic emissions. Geosci. Model Dev. 5, 1471-1492. https://doi.org/10.5194/gmd-5-1471 2012.

Harley, P., Greenberg, J., Niinemets, Ü., Guenther, A., 2007. Environmental controls over methanol emission from leaves. Biogeosciences. https://doi.org/10.5194/bg-4 1083-2007.

Henrot, A.-J., Stanelle, T., Schröder, S., Siegenthaler, C., Taraborrelli, D., Schultz, M.G., 2017. Implementation of the MEGAN (v2.1) biogenic emission model in the ECHAM6-HAMMOZ chemistry climate model. Geosci. Model Dev. 10, 903-926. https://doi.org/10.5194/gmd-10-903-2017.

Hörtnagl, L., Bamberger, I., Graus, M., Ruuskanen, T.M., Schnitzhofer, R., Walser, M., Unterberger, A., Hansel, A., Wohlfahrt, G., 2014. Acetaldehyde exchange above a managed temperate mountain grassland. Atmos. Chem. Phys. 14, 5369-5391. https://doi.org/10.5194/acp-14-5369-2014.

Hörtnagl, L., Clement, R., Graus, M., Hammerle, A., Hansel, A., Wohlfahrt, G., 2010. Dealing with disjunct concentration measurements in eddy covariance applications: a comparison of available approaches. Atmos. Environ. 44, 2024-2032. https://doi. org/10.1016/j.atmosenv.2010.02.042.

Hu, B., Jarosch, A.M., Gauder, M., Graeff-Hönninger, S., Schnitzler, J.P., Grote, R., Rennenberg, H., Kreuzwieser, J., 2018. VOC emissions and carbon balance of two bioenergy plantations in response to nitrogen fertilization: a comparison of Miscanthus and Salix. Environ. Pollut. https://doi.org/10.1016/j. envpol.2018.02.034.

Inomata, S., Tanimoto, H., 2010. A quantitative examination of the detection sensitivities of proton-transfer reaction mass spectrometry for gaseous 2-propanol and acetic acid. Bull. Chem. Soc. Jpn. https://doi.org/10.1246/bcsj.20100043.

Isaksen, I.S.A., Granier, C., Myhre, G., Berntsen, T.K., Dalsøren, S.B., Gauss, M., Klimont, Z., Benestad, R., Bousquet, P., Collins, W., Cox, T., Eyring, V., Fowler, D. Fuzzi, S., Jöckel, P., Laj, P., Lohmann, U., Maione, M., Monks, P., Prevot, A.S.H., Raes, F., Richter, A., Rognerud, B., Schulz, M., Shindell, D., Stevenson, D.S., Storelvmo, T., Wang, W.C., van Weele, M., Wild, M., Wuebbles, D., 2009. Atmospheric composition change: climate-Chemistry interactions. Atmos. Environ. 43, 5138-5192.

Jardine, K., Harley, P., Karl, T., Guenther, A., Lerdau, M., Mak, J.E., 2008. Plant physiological and environmental controls over the exchange of acetaldehyde between forest canopies and the atmosphere. Biogeosciences. https://doi.org/ 10.5194/bg-5-1559-2008.

Jardine, K., Yañez Serrano, A., Arneth, A., Abrell, L., Jardine, A., Artaxo, P., Alves, E., Kesselmeier, J., Taylor, T., Saleska, S., Huxman, T., 2011. Ecosystem-scale compensation points of formic and acetic acid in the central Amazon. Biogeosciences 8, 3709-3720. https://doi.org/10.1029/2001JD000676.

Kaimal, J.C., Finnigan, J., 1994. Atmospheric Boundary Layer Flows: Their Structure and Measurement. Oxford University Press, New York, p. 289.

Karl, M., Guenther, A., Koble, R., Leip, A., Seufert, G., 2009. A new European plantspecific emission inventory of biogenic volatile organic compounds for use in atmospheric transport models. Biogeosciences 6, 1059-1087.

Karl, T., Curtis, A.J., Rosenstiel, T.N., Monson, R.K., Fall, R., 2002. Transient releases of acetaldehyde from tree leaves - products of a pyruvate overflow mechanism? Plant Cell Environ. 25, 1121-1131.

Karl, T., Harren, F., Warneke, C., de Gouw, J., Grayless, C., Fall, R., 2005. Senescing grass crops as regional sources of reactive volatile organic compounds. J. Geophys. Res. Atmos. 110, D15302. https://doi.org/10.1029/2005JD005777.
Karl, T., Potosnak, M., Guenther, A., Clark, D., Walker, J., Herrick, J.D., Geron, C., 2004. Exchange processes of volatile organic compounds above a tropical rain forest: implications for modeling tropospheric chemistry above dense vegetation. J. Geophys. Res. Atmos. https://doi.org/10.1029/2004JD004738.

Kesselmeier, J., Bode, K., Gerlach, C., Jork, E.M., 1998. Exchange of atmospheric formic and acetic acids with trees and crop plants under controlled chamber and purified air conditions. Atmos. Environ. https://doi.org/10.1016/S1352-2310(97)00465-2.

König, G., Brunda, M., Puxbaum, H., Hewitt, C.N., Duckham, S.C., Rudolph, J., 1995. Relative contribution of oxygenated hydrocarbons to the total biogenic VOC emissions of selected mid-European agricultural and natural plant species. Atmos. Environ. https://doi.org/10.1016/1352-2310(95)00026-U.

Kottek, M., Grieser, J., Beck, C., Rudolf, B., Rubel, F., 2006. World Map of the KoppenGeiger climate classification updated. Meteorol. Z. 15, 259-263. https://doi.org/ 10.1127/0941-2948/2006/0130.

Laffineur, Q., Aubinet, M., Schoon, N., Amelynck, C., Müller, J.F., Dewulf, J., Van Langenhove, H., Steppe, K., Heinesch, B., 2012. Abiotic and biotic control of methanol exchanges in a temperate mixed forest. Atmos. Chem. Phys. https://doi. org/10.5194/acp-12-577-2012.

Langford, B., Cash, J., Acton, W.J.F., Valach, A.C., Hewitt, C.N., Fares, S., Goded, I., Gruening, C., House, E., Kalogridis, A.C., Gros, V., Schafers, R., Thomas, R., Broadmeadow, M., Nemitz, E., 2017. Isoprene emission potentials from European oak forests derived from canopy flux measurements: an assessment of uncertainties and inter-algorithm variability. Biogeosciences. https://doi.org/10.5194/bg-145571-2017.

Lerdau, M., Slobodkin, L., 2002. Trace gas emissions and species-dependent ecosystem services. Trends Ecol. Evol. 17, 309-312. https://doi.org/10.1016/S0169-5347(02) 02535-1.

Makkonen, R., Asmi, A., Kerminen, V.M., Boy, M., Arneth, A., Guenther, A., Kulmala, M., 2012. BVOC-aerosol-climate interactions in the global aerosol-climate model ECHAM5.5-HAM2. Atmos. Chem. Phys. https://doi.org/10.5194/acp-12-100772012.

Meier, U., 2001. Growth stages of mono-and dicotyledonous plants, BBCH Monograph. Federal Biological Research Centre for Agriculture and Forestry.

Mellouki, A., Wallington, T.J., Chen, J., 2015. Atmospheric chemistry of oxygenated volatile organic compounds: impacts on air quality and climate. Chem. Rev. 115, 3984-4014. https://doi.org/10.1021/cr500549n.

Messina, P., Lathière, J., Sindelarova, K., Vuichard, N., Granier, C., Ghattas, J., Cozic, A., Hauglustaine, D.A., 2016. Global biogenic volatile organic compound emissions in the ORCHIDEE and MEGAN models and sensitivity to key parameters. Atmos. Chem. Phys. 16, 14169-14202. https://doi.org/10.5194/acp-16-14169-2016.

Miresmailli, S., Zeri, M., Zangerl, A.R., Bernacchi, C.J., Berenbaum, M.R., Delucia, E.H., 2013. Impacts of herbaceous bioenergy crops on atmospheric volatile organic composition and potential consequences for global climate change. GCB Bioenergy. https://doi.org/10.1111/j.1757-1707.2012.01189.x.

Moncrieff, J.B., Massheder, J.M., De Bruin, H., Elbers, J., Friborg, T., Heusinkveld, B., Kabat, P., Scott, S., Soegaard, H., Verhoef, A., 1997. A system to measure surface fluxes of momentum, sensible heat, water vapour and carbon dioxide. J. Hydrol 188-189, 589-611. https://doi.org/10.1016/S0022-1694(96)03194-0.

Monson, R.K., Jones, R.T., Rosenstiel, T.N., Schnitzler, J.P., 2013. Why only some plants emit isoprene. Plant Cell Environ. 36, 503-516.

Moureaux, C., Debacq, A., Bodson, B., Heinesch, B., Aubinet, M., 2006. Annual net ecosystem carbon exchange by a sugar beet crop. Agric. For. Meteorol. https://doi. org/10.1016/j.agrformet.2006.05.009.

Mozaffar, A., Schoon, N., Bachy, A., Digrado, A., Heinesch, B., Aubinet, M., Fauconnier, M.-L., Delaplace, P., du Jardin, P., Amelynck, C., 2018. Biogenic volatile organic compound emissions from senescent maize leaves and a comparison with other leaf developmental stages. Atmos. Environ. 176, 71-81. https://doi.org/ 10.1016/j.atmosenv.2017.12.020.

Mozaffar, A., Schoon, N., Digrado, A., Bachy, A., Delaplace, P., du Jardin, P., Fauconnier, M.-L., Aubinet, M., Heinesch, B., Amelynck, C., 2017. Methanol emissions from maize: ontogenetic dependence to varying light conditions and guttation as an additional factor constraining the flux. Atmos. Environ. 152, 405-417. https://doi.org/10.1016/j.atmosenv.2016.12.041.

Müller, J.-F., Stavrakou, T., Wallens, S., De Smedt, I., Van Roozendael, M., Potosnak, M. J., Rinne, J., Munger, B., Goldstein, A., Guenther, A.B., 2008. Global isoprene emissions estimated using MEGAN, ECMWF analyses and a detailed canopy environment model. Atmos. Chem. Phys. 8, 1329-1341. https://doi.org/10.5194/ acp-8-1329-2008.

Niinemets, Ü., Fares, S., Harley, P., Jardine, K.J., 2014. Bidirectional exchange of biogenic volatiles with vegetation: emission sources, reactions, breakdown and deposition. Plant Cell Environ. 37, 1790-1809. https://doi.org/10.1111/pce.12322.

Niinemets, Ü., Monson, R.K., SpringerLink, 2013. Biology, Controls and Models of Tree Volatile Organic Compound Emissions, Tree Physiology, vol. 5. Springer Netherlands : Imprint: Springer, Dordrecht.

Niinemets, Ü., Reichstein, M., 2003. Controls on the emission of plant volatiles through stomata: a sensitivity analysis. J. Geophys. Res. D Atmos. 108.

Oderbolz, D.C., Aksoyoglu, S., Keller, J., Barmpadimos, I., Steinbrecher, R., Skjøth, C.A., Plaß-Dülmer, C., Prévôt, A.S.H., 2013. A comprehensive emission inventory of biogenic volatile organic compounds in Europe: improved seasonality and landcover. Atmos. Chem. Phys. 13, 1689-1712. https://doi.org/10.5194/acp-13-16892013.

Osborne, B., Saunders, M., Walmsley, D., Jones, M., Smith, P., 2010. Key questions and uncertainties associated with the assessment of the cropland greenhouse gas balance. Agric. Ecosyst. Environ. https://doi.org/10.1016/j.agee.2010.05.009.

Park, J.H., Fares, S., Weber, R., Goldstein, A.H., 2014. Biogenic volatile organic compound emissions during BEARPEX 2009 measured by eddy covariance and flux- 
gradient similarity methods. Atmos. Chem. Phys. 14, 231-244. https://doi.org/ 10.5194/acp-9-5505-2009.

Park, J.H., Goldstein, A.H., Timkovsky, J., Fares, S., Weber, R., Karlik, J., Holzinger, R., 2013. Active atmosphere-ecosystem exchange of the vast majority of detected volatile organic compounds. Science 80. https://doi.org/10.1126/science.1235053.

Personne, E., Loubet, B., Herrmann, B., Mattsson, M., Schjoerring, J.K., Nemitz, E., Sutton, M.A., Cellier, P., 2009. SURFATM-NH3: a model combining the surface energy balance and bi-directional exchanges of ammonia applied at the field scale. Biogeosciences. https://doi.org/10.5194/bg-6-1371-2009.

Pita, G., Gielen, B., Zona, D., Rodrigues, A., Rambal, S., Janssens, I.A., Ceulemans, R., 2013. Carbon and water vapor fluxes over four forests in two contrasting climatic zones. Agric. For. Meteorol. https://doi.org/10.1016/j.agrformet.2013.06.003.

Richards, N.A.D., Arnold, S.R., Chipperfield, M.P., Miles, G., Rap, A., Siddans, R., Monks, S.A., Hollaway, M.J., 2013. The Mediterranean summertime ozone maximum: global emission sensitivities and radiative impacts. Atmos. Chem. Phys. https://doi.org/10.5194/acp-13-2331-2013.

Rinne, J., Ammann, C., 2012. Disjunct eddy covariance method. Eddy Covariance. https://doi.org/10.1007/978-94-007-2351-1_10.

Ruuskanen, T.M., Müller, M., Schnitzhofer, R., Karl, T., Graus, M., Bamberger, I., Hörtnagl, L., Brilli, F., Wohlfahrt, G., Hansel, A., 2011. Eddy covariance VOC emission and deposition fluxes above grassland using PTR-TOF. Atmos. Chem. Phys. 11, 611-625. https://doi.org/10.5194/acp-9-5155-2009.

Sander, R., 2015. Compilation of Henry's law constants (version 4.0) for water as solvent. Atmos. Chem. Phys. 15, 4399-4981. https://doi.org/10.5194/acp-15-43992015.

Sartelet, K.N., Couvidat, F., Seigneur, C., Roustan, Y., 2012. Impact of biogenic emissions on air quality over Europe and North America. Atmos. Environ. 53, 131-141. https://doi.org/10.1016/j.atmosenv.2011.10.046.

Schade, G.W., Goldstein, A.H., 2001. Fluxes of oxygenated volatile organic compounds from a ponderosa pine plantation. J. Geophys. Res. D Atmos. 106, 3111-3123. https://doi.org/10.1029/2000JD900592.

Schwarz, K., Filipiak, W., Amann, A., 2009. Determining concentration patterns of volatile compounds in exhaled breath by PTR-MS. J. Breath Res. https://doi.org/ 10.1088/1752-7155/3/2/027002.

Spirig, C., Neftel, A., Ammann, C., Dommen, J., Grabmer, W., Thielmann, A., Schaub, A., Beauchamp, J., Wisthaler, A., Hansel, A., 2005. Eddy covariance flux measurements of biogenic VOCs during ECHO 2003 using proton transfer reaction mass spectrometry. Atmos. Chem. Phys. 5, 465-481. https://doi.org/10.5194/acp-5-4652005.

Squire, O.J., Archibald, A.T., Abraham, N.L., Beerling, D.J., Hewitt, C.N., Lathière, J., Pike, R.C., Telford, P.J., Pyle, J.A., 2014. Influence of future climate and cropland expansion on isoprene emissions and tropospheric ozone. Atmos. Chem. Phys. 14, 1011-1024. https://doi.org/10.5194/acp-10-8097-2010.

Stavrakou, T., Guenther, A., Razavi, A., Clarisse, L., Clerbaux, C., Coheur, P.F., Hurtmans, D., Karagulian, F., De Maziere, M., Vigouroux, C., Amelynck, C.,
Schoon, N., Laffineur, Q., Heinesch, B., Aubinet, M., Rinsland, C., Muller, J.F., 2011. First space-based derivation of the global atmospheric methanol emission fluxes. Atmos. Chem. Phys. 11, 4873-4898. https://doi.org/10.5194/acp-11-4873-2011.

Su, T., 1994. Parametrization of kinetic energy dependences of ion-polar molecule collision rate constants by trajectory calculations. J. Chem. Phys. https://doi.org/ 10.1063/1.466255.

Taipale, R., Ruuskanen, T.M., Rinne, J., 2010. Lag time determination in DEC measurements with PTR-MS. Atmos. Meas. Tech. 3, 853-862. https://doi.org/ 10.5194/amt-3-853-2010.

Tsimpidi, A.P., Trail, M., Hu, Y., Nenes, A., Russell, A.G., 2012. Modeling an air pollution episode in northwestern United States: identifying the effect of nitrogen oxide and volatile organic compound emission changes on air pollutants formation using direct sensitivity analysis. J. Air Waste Manag. Assoc. 62, 1150-1165.

Wang, R., Wu, T., Dai, W., Liu, H., Zhao, J., Wang, X., Huang, F., Wang, Z., Shi, C., 2015. Effects of straw return on C2-C5 non-methane hydrocarbon (NMHC) emissions from agricultural soils. Atmos. Environ. 100, 210-217. https://doi.org/10.1016/j. atmosenv.2014.10.051.

Warneke, C., De Gouw, J.A., Kuster, W.C., Goldan, P.D., Fall, R., 2003. Validation of atmospheric VOC measurements by proton-transfer-reaction mass spectrometry using a gas-chromatographic preseparation method. Environ. Sci. Technol. https:// doi.org/10.1021/es026266i.

Warneke, C., Luxembourg, S.L., de Gouw, J.A., Rinne, H.J.I., Guenter, A.B., Fall, R., 2002. Disjunct eddy covariance measurements of oxygenated volatile organic compounds fluxes from an alfalfa field before and after cutting. J. Geophys. Res. https://doi.org/10.1029/2001JD000594.

Wenda-Piesik, A., 2011. Volatile organic compound emissions by winter wheat plants (Triticum aestivum L.) under Fusarium spp. Infestation and various abiotic conditions. Pol. J. Environ. Stud. https://doi.org/10.1111/nph.14638.

Williams, J.E., van Velthoven, P.F.J., Brenninkmeijer, C.A.M., 2013. Quantifying the uncertainty in simulating global tropospheric composition due to the variability in global emission estimates of Biogenic Volatile Organic Compounds. Atmos. Chem. Phys. 13, 2857-2891. https://doi.org/10.5194/acp-13-2857-2013.

Wiß, F., Ghirardo, A., Schnitzler, J.P., Nendel, C., Augustin, J., Hoffmann, M., Grote, R., 2017. Net ecosystem fluxes and composition of biogenic volatile organic compounds over a maize field-interaction of meteorology and phenological stages. GCB Bioenergy. https://doi.org/10.1111/gcbb.12454.

Wohlfahrt, G., Amelynck, C., Ammann, C., Arneth, A., Bamberger, I., Goldstein, A.H., Gu, L., Guenther, A., Hansel, A., Heinesch, B., Holst, T., Hörtnagl, L., Karl, T., Laffineur, Q., Neftel, A., McKinney, K., Munger, J.W., Pallardy, S.G., Schade, G.W., Seco, R., Schoon, N., 2015. An ecosystem-scale perspective of the net land methanol flux: synthesis of micrometeorological flux measurements. Atmos. Chem. Phys. 15, 7413-7427. https://doi.org/10.5194/acp-15-7413-2015.

Ziemann, P.J., Atkinson, R., 2012. Kinetics, products, and mechanisms of secondary organic aerosol formation. Chem. Soc. Rev. https://doi.org/10.1039/c2cs35122f. 